\title{
The permeability and elastic moduli of tuff from Campi Flegrei, Italy: implications for ground deformation modelling
}

\author{
M. J. Heap ${ }^{1}$, P. Baud ${ }^{1}$, P. G. Meredith ${ }^{2}$, S. Vinciguerra ${ }^{3,4}$, and T. Reuschlé ${ }^{1}$ \\ ${ }^{1}$ Laboratoire de Déformation des Roches, Équipe de Géophysique Expérimentale, Institut de Physique de Globe de \\ Strasbourg (UMR7516 CNRS, Université de Strasbourg/EOST), 5 rue René Descartes, 67084 Strasbourg cedex, France \\ ${ }^{2}$ Rock \& Ice Physics Laboratory, Department of Earth Sciences, University College London, Gower Street, London WC1E \\ 6BT, UK \\ ${ }^{3}$ Department of Geology, University of Leicester, University Road, Leicester, LE1 7RH, UK \\ ${ }^{4}$ British Geological Survey, Environmental Science Centre, Keyworth, Nottingham, NG12 5GG, UK
}

Correspondence to: M. J. Heap (heap@ unistra.fr)

Received: 8 July 2013 - Published in Solid Earth Discuss.: 19 July 2013

Revised: 29 November 2013 - Accepted: 3 December 2013 - Published: 24 January 2014

\begin{abstract}
The accuracy of ground deformation modelling at active volcanoes is a principal requirement in volcanic hazard mitigation. However, the reliability of such models relies on the accuracy of the rock physical property (permeability and elastic moduli) input parameters. Unfortunately, laboratory-derived values on representative rocks are usually rare. To this end we have performed a systematic laboratory study on the influence of pressure and temperature on the permeability and elastic moduli of samples from the two most widespread lithified pyroclastic deposits at the Campi Flegrei volcanic district, Italy. Our data show that the water permeability of Neapolitan Yellow Tuff and a tuff from the Campanian Ignimbrite differ by about 1.5 orders of magnitude. As pressure (depth) increases beyond the critical point for inelastic pore collapse (at an effective pressure of 10$15 \mathrm{MPa}$, or a depth of about $750 \mathrm{~m}$ ), permeability and porosity decrease significantly, and ultrasonic wave velocities and dynamic elastic moduli increase significantly. Increasing the thermal stressing temperature increases the permeability and decreases the ultrasonic wave velocities and dynamic elastic moduli of the Neapolitan Yellow Tuff; whereas the tuff from the Campanian Ignimbrite remains unaffected. This difference is due to the presence of thermally unstable zeolites within the Neapolitan Yellow Tuff. For both rocks we also find, under the same pressure conditions, that the dynamic (calculated from ultrasonic wave velocities) and static (calculated from triaxial stress-strain data) elastic moduli differ significantly. The choice of elastic moduli in ground deforma-
\end{abstract}

tion modelling is therefore an important consideration. While we urge that these new laboratory data should be considered in routine ground deformation modelling, we highlight the challenges for ground deformation modelling based on the heterogeneous nature (vertically and laterally) of the rocks that comprise the caldera at Campi Flegrei.

\section{Introduction}

Monitoring ground deformation, the surface expression of deeper magmatic and/or hydrothermal activity, at active volcanoes is an important tool in volcanic hazard forecasting and mitigation. Ground deformation at a volcano (measured by global positioning system (GPS) satellites, interferometric synthetic aperture radar (InSAR), tiltmeters, or electronic distance metres (EDM)) are typically analysed using inverse problem models that consider a source (e.g. a magma chamber, a zone of overpressurized fluids, or a combination of the two) embedded within a homogenous elastic or viscoelastic half-space (e.g. Mogi, 1958; Dzurisin, 2006; Hurwitz et al., 2007). These models yield important information regarding the location, shape, and volume/pressure changes of the source. The accuracy of such modelling relies on the accuracy of the rock physical property input parameters (typically elastic moduli and permeability, depending on the type of model). Even small changes in the values of key controlling parameters can lead to large differences in the rate, 


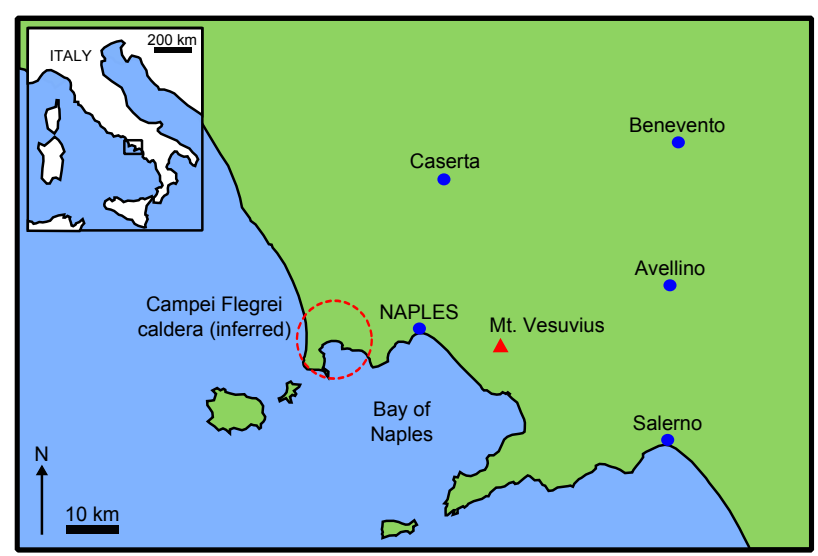

Fig. 1. Map showing the location of the inferred Campi Flegrei caldera and the proximity of Naples to both the Campi Flegrei caldera and Mt. Vesuvius. The Neapolitan Yellow Tuff used in this study was sourced from an open quarry within the inferred CF caldera at Monte San Severino (i.e. within the red circle), while the Grey Campanian Ignimbrite was sourced from an open quarry to the north-west of the town of Caserta (the blocks used in this study are the same as those used in Heap et al., 2012).

magnitude, and geometry of ground surface deformation (e.g. Hurwitz et al., 2007). For instance, a recent contribution using viscoelastic modelling to better understand flank motion and summit subsidence at Kỉlauea (Hawai'i) showed that deformation rates are enhanced when the elastic moduli input parameters are lowered (Plattner et al., 2013). Furthermore, homogenous half-space models, by definition, assume that all the rocks that comprise the volcano have identical physical properties. However, volcanoes are built from successive eruptive episodes and thus the physical properties of the rock strata that form the edifice are likely to span a wide range. For this reason, conventional homogenous halfspace modelling at volcanoes has recently been considered an oversimplification that could lead to misinterpretation of the derived source parameters (Manconi et al., 2007, 2010). For instance, Manconi et al. (2010) showed that this "standard" approach can lead to inaccurate values for the source volume changes. Therefore, models that consider mechanical heterogeneities (e.g. Manconi et al., 2007, 2010) require a good knowledge of the breadth of elastic moduli that can be expected for representative rocks, and thermodynamic and magmatic-hydrothermal models (e.g. Hurwitz et al., 2007; Todesco et al., 2010) require accurate values of their permeability and elastic moduli. However, such laboratory data are commonly scarce or absent.

The densely populated (about 3 million) Neapolitan area, southern Italy, is in a state of constant threat provided by the proximity of Mt. Vesuvius and the increasingly restless Campi Flegrei (CF) volcanic district (Ricci et al., 2013; Fig. 1). The eruptive history of the CF volcanic district can be characterized by two major eruptions: (1) the eruption re- lated to the emplacement of the Campanian Ignimbrite about $39000 \mathrm{yr}$ ago (De Vivo et al., 2001) and, (2) the eruption of the Neapolitan Yellow Tuff (NYT) about $15000 \mathrm{yr}$ ago (Deino et al., 2004); although the area has been volcanically active for more than $300000 \mathrm{yr}$ (Rolandi et al., 2003).

Today, the CF volcanic district is dominated by a resurgent, nested caldera (Fig. 1) that hosts a large, shallow $(<4 \mathrm{~km})$ hydrothermal system (e.g. De Natale et al., 2006). The CF caldera is considered to have formed due to collapse following (1) both of the major eruptions (e.g. Barberi et al., 1991; Orsi et al., 1996) or, (2) the eruption of the NYT only (see Rolandi et al., 2003 and references therein). In the latter hypothesis, the Campanian Ignimbrite is thought to be the result of eruptive events originating from pre-existing neotectonic faults formed during the Apennine uplift (De Vivo et al., 2001; Rolandi et al., 2003). Although there has not been an eruption for almost $500 \mathrm{yr}$ (since the Monte Nuovo eruption of $1538 \mathrm{AD}$ ), $\mathrm{CF}$ has become increasingly restless and is densely monitored by permanent seismic and ground deformation networks. In recent times, two major episodes of unrest have occurred, between 1969-1972 and 1982-1984 (Bianchi et al., 1987; Bonafede, 1991). Surface uplift, on the order of several metres (bradyseism), and accompanying earthquakes in 1984 led to the evacuation of the town of Pozzuoli. Since then, there has been an overall subsidence trend (e.g. see Fig. 2 in D'Auria et al., 2011), periodically interrupted by small (centimetre-scale) and short-lived (months) uplifts in 1989, 1994, 2000-2001 (e.g. Lanari et al., 2004; Bianco et al., 2004; D'Auria et al., 2011), and 2004-2006 (e.g. Saccorotti et al., 2007; Trasatti et al., 2008; D'Auria et al., 2011). However, the interpretation of long-term and short-term ground deformation patterns at $\mathrm{CF}$ is a matter of debate (see De Natale et al., 2001, and De Natale et al., 2006, for reviews on the topic). Models to explain the origin of the uplift can be broadly divided into two camps: those that consider solely the input of magma at depth (e.g. Berrino et al., 1984; Bonafede et al., 1986; Bianchi et al., 1987) and those that invoke an interaction between magma and fluids (magmatic-hydrothermal models and thermodynamic models; e.g. Bonafede, 1991; Gaeta et al., 1998; Bonafede and Mazzanti, 1998; De Natale et al., 2001; Lundgren et al., 2001; Troise et al., 2001; Gaeta et al., 2003; Chiodini et al., 2003; Battaglia et al., 2006; Gottsmann et al., 2006; Troise et al., 2007; Bodnar et al., 2007; Lima et al., 2009; Todesco et al., 2010; D'Auria et al., 2011; Troiano et al., 2011; Chiodini et al., 2012). The latter category can be broken down further into models that require the input of fresh magma from depth (e.g. Gaeta et al., 1998) and those that consider magma body cooling and concomitant crystallization (e.g. Bodnar et al., 2007; Lima et al., 2009). Other models account for the surface deformation by invoking an interaction between the pressure source and caldera boundary fractures (e.g. De Natale and Pingue, 1993; Beauducel et al., 2004) or mechanical heterogeneities (e.g. Manconi et al., 2010). 


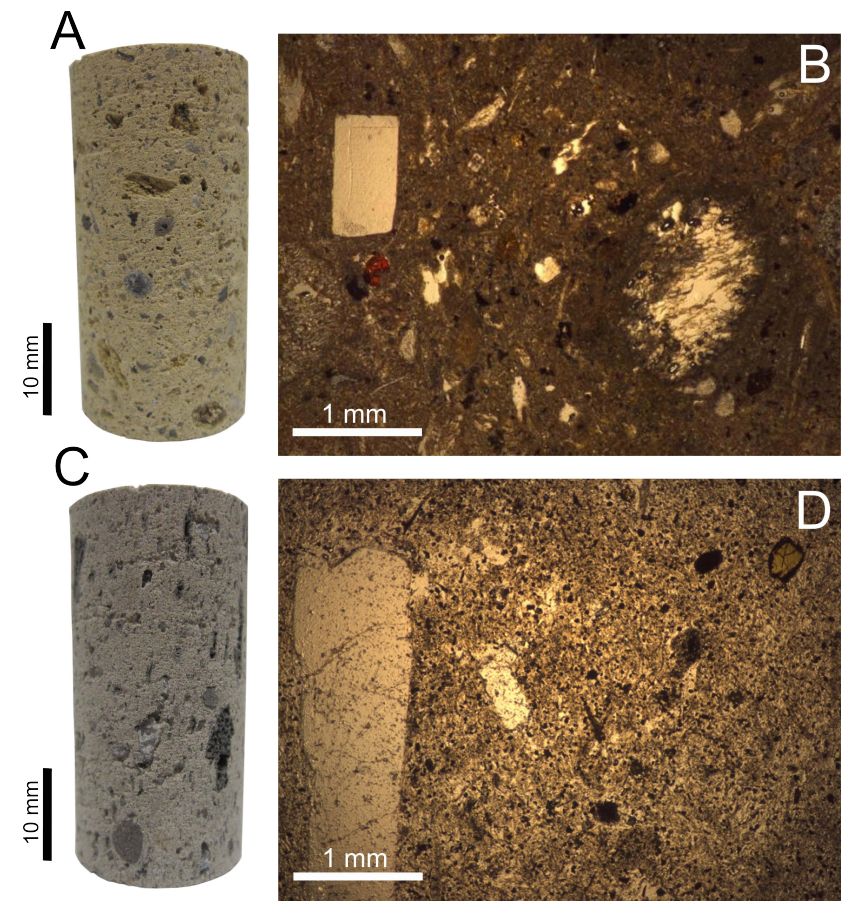

Fig. 2. Photographs and optical microscopy images of the ascollected Neapolitan Yellow Tuff (A and B) and Grey Campanian Ignimbrite ( $\mathbf{C}$ and $\mathbf{D})$. The photomicrographs are taken from Heap et al. (2012).

While we note that the goal of this contribution is not to critically review the numerous models invoked to explain the ground deformation at $\mathrm{CF}$, we highlight that the accuracy of all these models relies on accuracy of the rock physical property input parameters. Unfortunately, published laboratory investigations on the physical properties of representative materials from the CF caldera are rare. Values of permeability have, thus far, either been inferred from in situ observations (Rosi and Sbrana, 1987) or have been taken from experiments conducted on NYT under ambient pressure conditions (Ascolese et al., 1993a, b; Peluso and Arienzo, 2007). In the most recent study, Peluso and Arienzo (2007) measured the permeability of NYT at ambient pressure to be between $2.0 \times 10^{-15}$ and $6.3 \times 10^{-17} \mathrm{~m}^{2}$ (the range of porosity was between 48 and $52 \%$ ). However, not only are the deposits within the CF caldera present at depth (which is likely to severely influence their permeability), but it is known that the permeability of lithified pyroclastic deposits can be highly variable (a variety of representative materials should therefore be measured), depending on their degree of lithification (Vinciguerra et al., 2009). We also highlight that permeability data of borehole samples are presented in an open access report (Giberti et al., 2006). This report shows, for the San Vito 1 borehole, that the permeability can range from $10^{-13} \mathrm{~m}^{2}$ at the surface to $10^{-16} \mathrm{~m}^{2}$ at a depth of almost $3000 \mathrm{~m}$.
Elastic moduli are generally assumed, or extrapolated from seismic tomography studies (e.g. Chiarabba and Moretti, 2006; Vinciguerra et al., 2006). Typically, Poisson's ratio is taken as 0.3 and shear modulus as $5 \mathrm{GPa}$ (e.g. De Natale et al., 1991). However, dynamically-determined elastic moduli (i.e. those calculated from ultrasonic wave velocities) may not represent the most appropriate values to use in volcano ground deformation modelling. Deformation caused by a volcanic source proceeds quasi-statically rather than dynamically and therefore static elastic moduli are likely to be the most appropriate input parameters (Heap et al., 2009; Manconi et al., 2010). It is well known that dynamic and static moduli differ as a result of the large differences in the frequency at which they are measured (Simmons and Brace, 1965; Cheng and Johnston, 1981; Eissa and Kazi, 1989; Ciccotti and Mulargia, 2004; Ciccotti et al., 2004). Static elastic moduli for representative materials from $\mathrm{CF}$ are not yet available (Manconi et al., 2010).

The pyroclastic deposits that comprise the caldera at $\mathrm{CF}$ are exposed to elevated temperatures, as evidenced by two-dimensional conductive/convective numerical modelling (Wohletz et al., 1999), seismic attenuation tomography (de Lorenzo et al., 2001), and infrared imaging (Chiodini et al., 2007). Surface geothermal gradients of about 150$200{ }^{\circ} \mathrm{C} \mathrm{km}^{-1}$ are estimated (for the first $1.5 \mathrm{~km}$ ) and, at the edge of the hydrothermal system, a temperature of $420^{\circ} \mathrm{C}$ was measured at a depth of $3 \mathrm{~km}$ (AGIP borehole San Vito 1, de Lorenzo et al., 2001). It has been shown previously that thermal stresses can increase the permeability (e.g. HomandEtienne and Troalen, 1984; Jones et al., 1997; David et al., 1999; Nara et al., 2011) and decrease the Young's modulus (e.g. Keshavarz et al., 2010) of rock. This is usually interpreted as being a consequence of the formation of new microcracks due to the build-up of internal thermal stresses. Volcanic rocks are persistently challenged by elevated temperatures due to their proximity to large permanent heat sources, and the fluctuations in temperature caused by the movement of magma, and are therefore especially prone to thermal microcracking. Furthermore, many fine-grained pyroclastic deposits can be further jeopardized by high temperatures due to the presence of thermally unstable zeolites (Heap et al., 2012). Since zeolitization promoted lithification, the loss of zeolites can impose dramatic consequences on rock physical properties. Recent data has shown that NYT becomes structurally unstable upon exposure to high $\left(100-750^{\circ} \mathrm{C}\right)$ temperatures, resulting in a severe decrease in both tensile and compressive strength (Heap et al., 2012). A recent contribution by Manconi et al. (2010) highlighted the need for the evaluation of the temperature-dependence of the material properties of the rocks at $\mathrm{CF}$.

For the reasons outlined above we have conducted a systematic study of the influence of pressure and temperature on the physical properties (permeability, porosity, ultrasonic velocities, and elastic moduli) of two lithified pyroclastic deposits (one zeolitized) from CF. We first present 
Table 1. Summary of the ambient pressure, as-collected physical properties of NYT and WGI. "Dry" indicates measurements on samples that were dried in a vacuum oven for at least $24 \mathrm{~h}$; the measurements were then performed under ambient laboratory humidity. "Wet" indicates measurements on samples that were vacuum-saturated with distilled water.

\begin{tabular}{lcc}
\hline & $\begin{array}{c}\text { Neapolitan Yellow } \\
\text { Tuff (NYT) }\end{array}$ & $\begin{array}{c}\text { Grey Campanian } \\
\text { Ignimbrite (WGI) }\end{array}$ \\
\hline connected porosity [\%] & 43.8 & 48.5 \\
dry bulk sample density $\left[\mathrm{kg} \mathrm{m}^{-3}\right.$ ] & 1270 & 1330 \\
dry $P$ wave velocity $\left[\mathrm{km} \mathrm{s}^{-1}\right.$ ] & 2.29 & 2.31 \\
wet $P$ wave velocity $\left[\mathrm{km} \mathrm{s}^{-1}\right.$ ] & 2.60 & 2.56 \\
dry $S$ wave velocity $\left[\mathrm{km} \mathrm{s}^{-1}\right]$ & 1.25 & 1.28 \\
wet $S$ wave velocity $\left[\mathrm{km} \mathrm{s}^{-1}\right]$ & 1.30 & 1.33 \\
dry $V_{P} / V_{S}$ & 1.84 & 1.80 \\
wet $V_{P} / V_{S}$ & 2.00 & 1.93 \\
dry dynamic Young's & 5.07 & 5.58 \\
modulus [GPa] & & 8.42 \\
wet dynamic Young's & 7.68 & \\
modulus [GPa] & & 0.28 \\
dry dynamic Poisson's ratio & 0.28 & 0.31 \\
wet dynamic Poisson's ratio & 0.33 & 2.19 \\
dry dynamic shear modulus [GPa] & 1.97 & 3.20 \\
wet dynamic shear modulus [GPa] & 2.88 & 9.23 \\
dry unconfined compressive strength [MPa] & 3.47 & \\
(from Heap et al., 2012) & & \\
\hline
\end{tabular}

the investigated materials and methods. We then present our experimental results before discussing our data in terms of ground deformation modelling at $\mathrm{CF}$.

\section{Materials investigated}

Our experiments were performed on samples of NYT and Grey Campanian Ignimbrite (WGI), sampled from the two most abundant and widespread volcanic deposits in the CF volcanic district. NYT was sourced from an open quarry within the inferred CF caldera at Monte San Severino (i.e. within the red circle in Fig. 1), while the WGI was sourced from an open quarry to the north-west of the town of Caserta (the blocks used in this study are the same as those used in Heap et al., 2012). In this paper we refer to both lithified pyroclastic rocks as "tuffs".

NYT and WGI contain average connected porosities of 44 and $49 \%$, respectively (measured using the triple weight water saturation technique; Guéguen and Palciauskas, 1994). We note that, although our samples are small compared to the volume of the natural deposits, a report by Giberti et al. (2006) showed that the porosity of 12 and $125 \mathrm{~cm}^{3}$ samples were very similar, for a wide range of material from CF. Photographs and optical microscopy photomicrographs of the samples are provided as Fig. 2 and their ambient pressure, "as-collected" (i.e. "natural" samples that have undergone no heating or deformation) physical properties are listed in Table 1. NYT (Fig. 2a, b), a trachytic pyroclastic deposit characterized by both pyrogenic and authigenic phases (de
Gennaro et al., 2000), contains phenocrysts of sanidine, plagioclase, clinopyroxene, biotite, and minor amounts of Timagnetite and apatite within a matrix of pumiceous lapilli and glassy ash (glass shards and blocky shaped glass fragments). X-ray diffraction pattern analysis has indicated the presence of phillipsite, chabazite, and analcime (Heap et al., 2012). The mean content of these zeolites in NYT can exceed $50 \%$ (e.g. de Gennaro et al., 1990, 2000). WGI (Fig. 2c and d), feldspathized by authigenic mineralization processes, is made up of reversely graded black scoriae embedded in an ashy matrix with subordinate lithics and crystals (Cappelletti et al., 2003; Langella et al., 2013). WGI contains hypidiomorphic phenocrysts of alkali-feldspars with minor amounts of clinopyroxene, as well as microlites of alkalifeldspar, Ti-magnetite and apatite. The matrix comprises well-sorted glass shards with occasional accretionary ash clots and porous lapilli fragments (Heap et al., 2012, and references therein). Although WGI does not contain any zeolites, we note that portions of the Campanian Ignimbrite are pervasively zeolitized (e.g. see Langella et al., 2013).

\section{Experimental methods}

As mentioned above, the caldera at CF hosts a large, shallow $(<4 \mathrm{~km})$ hydrothermal system (e.g. De Natale et al., 2006). Indeed, laboratory studies have demonstrated that the watersaturated ultrasonic velocities of tuffs from $\mathrm{CF}$ are more representative of the in situ values than "dry" (measurements conducted on oven dried samples at ambient laboratory 
Table 2. Summary of the estimated measurement accuracy.

\begin{tabular}{ll}
\hline measurement & accuracy \\
\hline confining pressure $[\mathrm{Pa}]$ & \pm 100000 (UCL) \\
& \pm 10000 (Strasbourg) \\
pore fluid pressure $[\mathrm{Pa}]$ & \pm 10000 \\
pore fluid volume $\left[\mathrm{m}^{3}\right]$ & $\pm 1.0 \times 10^{-12}$ \\
LVDT displacement [m] & \pm 0.000001 \\
axial stress $[\mathrm{Pa}]$ & \pm 10000 \\
original sample dimensions $[\mathrm{m}]$ & \pm 0.00001 \\
\hline
\end{tabular}

humidity) ultrasonic velocities (Zamora et al., 1994; Vanorio et al., 2005; Vinciguerra et al., 2006). Since the tuffs of CF are present at depth, and are likely to contain a fluid phase (e.g. a mixture of meteoric water and seawater contaminated by rising magmatic gases, see Valentino et al., 1999), we consider experimental values on pressurized, water-saturated samples as the most representative. Our experimental program was twofold. (1) Hydrostatic (i.e. $\sigma_{1}=\sigma_{2}=\sigma_{3}$ ) experiments to measure changes in permeability, porosity, ultrasonic wave velocities, and dynamic elastic moduli with increasing effective pressure (Peff, from 5 to $50 \mathrm{MPa}$ ) on samples that had been thermally stressed to a range of temperatures (from as-collected to $1000^{\circ} \mathrm{C}$ ). (2) Constant strain rate conventional triaxial (i.e. $\sigma_{1}>\sigma_{2}=\sigma_{3}$ ) deformation experiments at a Peff of $5 \mathrm{MPa}$ to measure static elastic moduli. Importantly, we measure both static and dynamic elastic moduli at the same Peff ( $=5 \mathrm{MPa})$ so that the values can be easily compared. All our experiments were performed at room temperature (while this may not accurately represent the natural case, we note that, to explore the influence of temperature on the physical properties of the tuffs, we conducted experiments on samples thermally stressed to a range of temperatures).

Experimental data are subject to error as a result of the accuracy of the various transducers. Estimations of the accuracy of the measurements of this study are listed in Table 2. The errors are extremely small and lead to error bars that are smaller than the data points in the figures provided in this study. However, we note that measurement errors are dwarfed by the natural sample variability of the tuffs (i.e. the natural variability of samples cored from the same block of material). Estimations of the natural sample variability of the tuffs used this study are provided in Table 3. While one of the goals of this contribution is to demonstrate the variability of different tuffs from the CF volcanic district, we strived to minimize the variability between samples cored from the same block by (1) coring many samples and selecting those within a strict porosity range, (2) discarding samples with obvious, large heterogeneities and, (3) discarding samples with anomalous $P$ wave velocities. Using these sample selection guidelines, our experiments under different conditions (dif-
Table 3. Expected natural variability between tuff samples cored from the same block. Note that these are not "errors" in the measurements. Measurement accuracies (Table 2) are insignificant compared to the natural sample variability, despite efforts to reduce the variability between samples cored from the same block of material (see text for details).

\begin{tabular}{ll}
\hline & expected natural variability \\
\hline Young's modulus $[\mathrm{GPa}]$ & \pm 0.5 \\
Poisson's ratio & \pm 0.05 \\
shear modulus [GPa] & \pm 0.5 \\
water permeability $\left[\mathrm{m}^{2}\right]$ & $\pm 1.0 \times 10^{-14}$ \\
$P$ wave velocity $\left[\mathrm{km} \mathrm{s}^{-1}\right]$ & \pm 0.1 \\
$S$ wave velocity $\left[\mathrm{km} \mathrm{s}^{-1}\right]$ & \pm 0.1 \\
\hline
\end{tabular}

ferent thermal stressing temperatures and pressures) can be compared with the greatest confidence.

\subsection{Hydrostatic experiments}

Hydrostatic experiments were performed in the Rock \& Ice Physics Laboratory (RIPL) at University College London (UCL) using a $300 \mathrm{MPa}$ hydrostatic pressure vessel equipped with two $70 \mathrm{MPa}$ servo-controlled pore fluid intensifiers or volumometers (Fig. 3, see also Kolzenburg et al., 2012). The apparatus is designed to measure permeability, porosity, and ultrasonic wave velocities contemporaneously. In our experiments we chose an experimental pressure range of 5-50 MPa (i.e. up to a depth of about $3.5 \mathrm{~km}$ ).

Cylindrical samples, $25 \mathrm{~mm}$ in diameter and nominally $40 \mathrm{~mm}$ in length, were all cored from the same set of blocks and in the same orientation. Samples were precision ground so that their end faces were flat and parallel. Prior to experimentation, samples were either (1) held at ambient temperature (as-collected) or, (2) thermally stressed to pre-determined temperatures of 100, 200,300,500,750, or $1000^{\circ} \mathrm{C}$ (note: NYT could not be tested after exposure to $1000^{\circ} \mathrm{C}$ due to a severe volume reduction). Thermal stressing was achieved by heating the sample to the target temperature at a rate of $1^{\circ} \mathrm{C} / \mathrm{min}$, holding the temperature constant for $60 \mathrm{~min}$, and then cooling at the same rate. Once at room temperature, all samples were vacuum-saturated in distilled water prior to experimentation. The measured sample was then inserted into a nitrile rubber jacket and fixed between the two endcaps. The sample assembly was then lowered into the pressure vessel. Once inside the setup, the confining pressure $\left(P_{\mathrm{c}}\right)$ and the pore fluid (distilled water) pressures $\left(P_{\mathrm{p}}\right)$ in both the "upstream" $\left(P_{\text {up }}\right)$ and "downstream" $\left(P_{\text {down }}\right)$ pore volumometers were increased to 10 and $5 \mathrm{MPa}$, respectively. The confining and pore pressures were increased slowly to avoid damaging the sample, and care was taken to ensure the sample was not pressurized beyond the maximum effective pressure targeted for the experiments ( $5 \mathrm{MPa})$. For the purpose of this study we apply the simple effective pressure 


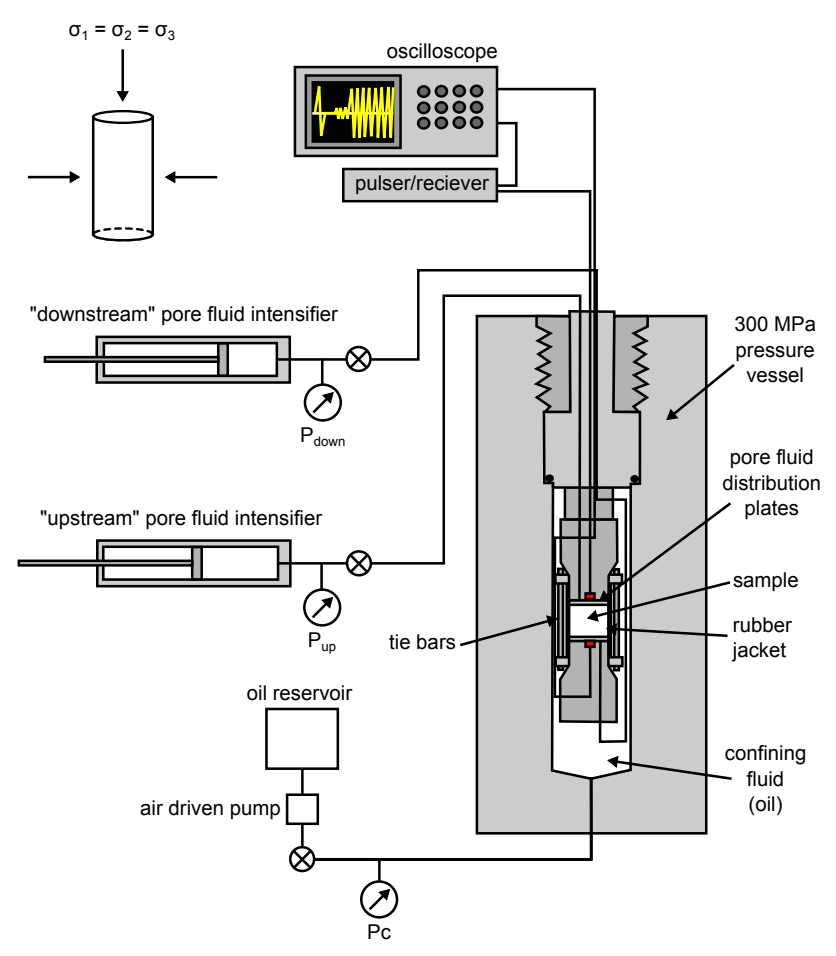

Fig. 3. Schematic diagram of the permeameter at the Rock \& Ice Physics Laboratory (RIPL), University College London. Schematic is not to scale.

law of Peff $=P_{\mathrm{c}}-\alpha P_{\mathrm{p}}$, assuming that poroelastic constant $\alpha=1$ (Guéguen and Palciauskas, 1994). The sample was left for $30 \mathrm{~min}$ at an effective pressure of $5 \mathrm{MPa}$ to ensure microstructural equilibration and complete saturation.

Once equilibration at $\mathrm{Peff}=5 \mathrm{MPa}$ was complete, the first ultrasonic measurements were taken. Ultrasonic waves velocities were measured via PZT (lead-zirconate-titanate) piezoelectric $P$ and $S$ wave transducer crystals housed in the sample endcaps (Fig. 3) using an Agilent Technologies $1.5 \mathrm{GHz}$ "Infiniium" digital storage oscilloscope and a JSR DPR300 $35 \mathrm{MHz}$ ultrasonic pulser/receiver. All ultrasonic wave arrival times were individually picked as the first deviation from the baseline signal. Dynamic elastic moduli were calculated from the resultant ultrasonic wave velocities using the following formulae (Guéguen and Palciauskas, 1994):

$$
\begin{aligned}
E_{\mathrm{d}} & =\rho \frac{V_{S}^{2}\left(3 V_{P}^{2}-4 V_{S}^{2}\right)}{V_{P}^{2}-V_{S}^{2}}, \\
v_{\mathrm{d}} & =\frac{V_{P}^{2}-2 V_{S}^{2}}{2\left(V_{P}^{2}-V_{S}^{2}\right)}, \\
\mu_{\mathrm{d}} & =\frac{E_{\mathrm{d}}}{2\left(1+v_{\mathrm{d}}\right)} .
\end{aligned}
$$

where $E_{\mathrm{d}}$ is Young's modulus, $v_{\mathrm{d}}$ is Poisson's ratio, $\mu_{\mathrm{d}}$ is the shear modulus, $\rho$ is the bulk sample density and $V_{P}$ and $V_{S}$ are the $P$ and $S$ wave velocities, respectively.
Water permeability measurements were made by imposing a $1 \mathrm{MPa}$ pressure difference across the jacketed sample. To achieve this, $P_{\text {up }}$ and $P_{\text {down }}$ were set at 4.5 and $5.5 \mathrm{MPa}$, respectively. The volumometers were then allowed to move full stroke $\left(10 \mathrm{~cm}^{3}\right)$ and steady-state flow was only assumed when the flow rate was constant over a protracted period. Water permeability ( $\kappa_{\text {water }}$ ) was then calculated directly from Darcy's law:

$$
\frac{Q}{A}=\frac{\kappa_{\text {water }}}{\eta L}\left(P_{\text {up }}-P_{\text {down }}\right),
$$

where $Q$ is the fluid volume flux, $A$ is the cross-sectional area of the sample, $\eta$ is the viscosity of the pore fluid (taken as $\left.8.94 \times 10^{-4} \mathrm{~Pa} . \mathrm{s}\right), L$ is the length of the sample, and $P_{\text {up }}$ and $P_{\text {down }}$ are the pore pressures at the "upstream" and "downstream" ends of the sample, respectively.

Once the permeability measurement was complete, the "downstream" volumometer was isolated and the "upstream" volumometer was set back at $5 \mathrm{MPa}$. The $P_{\mathrm{c}}$ was then slowly increased to $15 \mathrm{MPa}$. By monitoring the movement of the "upstream" volumometer the porosity change from Peff = $5 \mathrm{MPa}$ to Peff $=10 \mathrm{MPa}$ could be accurately calculated. The sample was then left for $30 \mathrm{~min}$ at the new pressure to ensure microstructural equilibration. Once equilibration was complete, the ultrasonic measurements for Peff $=10 \mathrm{MPa}$ were taken. This procedure was repeated for every $5 \mathrm{MPa}$ Peff increment up to $50 \mathrm{MPa}$.

During our experiments, the length of the sample $L$ and the cross-sectional area $A$ will change due to the compaction of the sample at elevated pressure. We have corrected for this (in our calculations of permeability and ultrasonic wave velocities) using the volume reduction of our sample (as measured by the water expelled from the sample) at each pressure interval, assuming isotropic compaction. Although one sample was used per thermal-stressing temperature, we reiterate that great care was taken during sample selection to exclude samples that contained large heterogeneities or anomalous connected porosities/ $P$ wave velocities.

\subsection{Triaxial deformation experiments}

Constant strain rate $\left(1.0 \times 10^{-5} \mathrm{~s}^{-1}\right)$ conventional (i.e. $\sigma_{1}$ $>\sigma_{2}=\sigma_{3}$ ) triaxial experiments were performed on ascollected cylindrical samples of the two tuffs $(20 \mathrm{~mm}$ in diameter and nominally $40 \mathrm{~mm}$ in length). Samples were cored from the same blocks and in the same direction as for the hydrostatic experiments described in the previous section. The samples were precision ground so that their end faces were flat and parallel. Both experiments were performed in the conventional triaxial deformation apparatus (Fig. 4) at the Laboratoire de Déformation des Roches (Université de Strasbourg) at a Peff of $5 \mathrm{MPa}\left(P_{\mathrm{p}}\right.$ of $5 \mathrm{MPa}$ and a $P_{\mathrm{c}}$ of $\left.10 \mathrm{MPa}\right)$. Axial stress and strain were monitored continuously using a load cell and an LVDT displacement transducer, respectively. Pore volume change (used as a proxy for volumetric strain, 


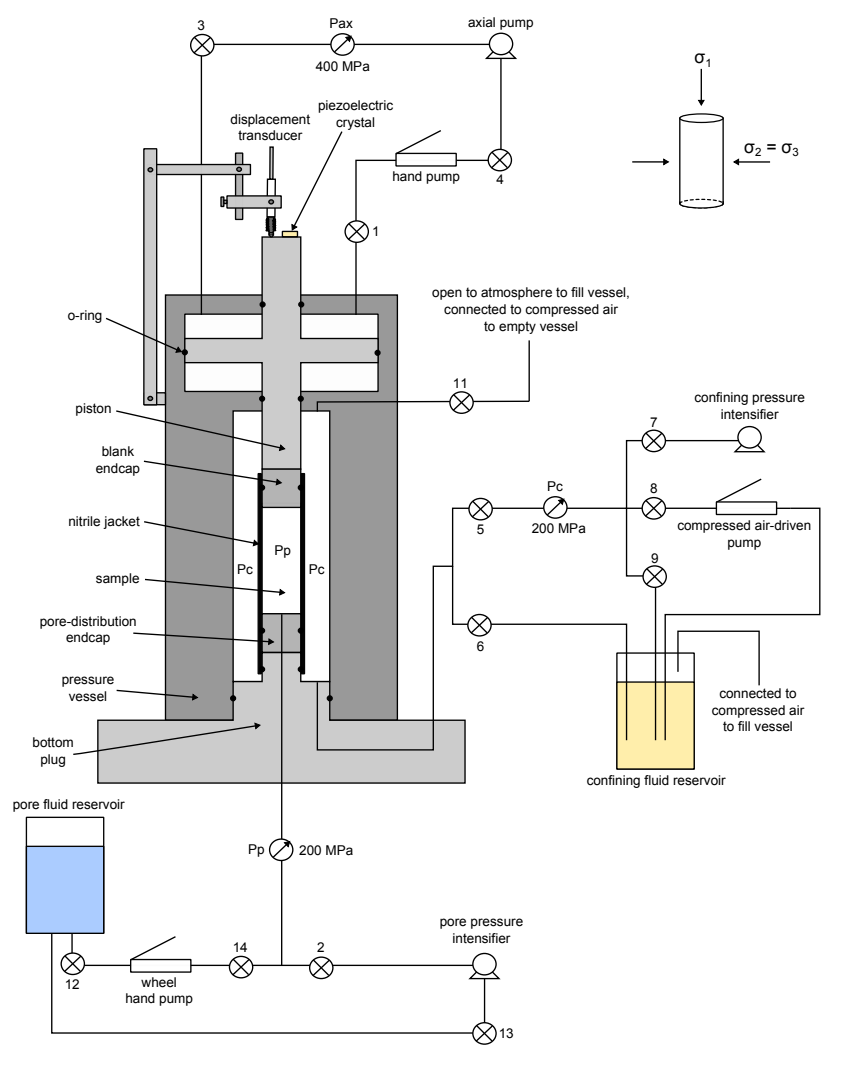

Fig. 4. Schematic diagram of the triaxial deformation apparatus at the Laboratoire de Déformation des Roches, Université de Strasbourg. Schematic is not to scale.

$\varepsilon_{v}$ ) was monitored using a pore pressure intensifier, and the output of acoustic emissions (AEs) by a piezoelectric transducer crystal (located on the top of the piston) using a Physical Acoustics USB AE Node. AEs are high frequency elastic wave packets generated by the rapid release of strain energy such as during brittle microfracturing (see Lockner, 1993 for a review). During experimentation, an AE hit was recorded if a signal exceeded the set threshold of $40 \mathrm{~dB}$. The AE "energy" (the area under the received $\mathrm{AE}$ waveform envelope) of each received AE signal was provided by the AEwin software. In this study we will adopt the convention that compressive stresses and compactive strains are positive.

Static Young's moduli $\left(E_{\mathrm{s}}\right)$ and Poisson's ratio $\left(v_{\mathrm{s}}\right)$ were then calculated from the resultant stress-strain data, following the method of Heap and Faulkner (2008). We take both from the quasi-linear elastic regions of our tangent modulus curves (i.e. those regions where the moduli did not change). Static Poisson's ratio is given by

$v_{\mathrm{s}}=-\frac{\varepsilon_{\mathrm{r}}}{\varepsilon_{\mathrm{a}}}$,

where

$\varepsilon_{\mathrm{r}}=\frac{\varepsilon_{\mathrm{v}}-\varepsilon_{\mathrm{a}}}{2}$
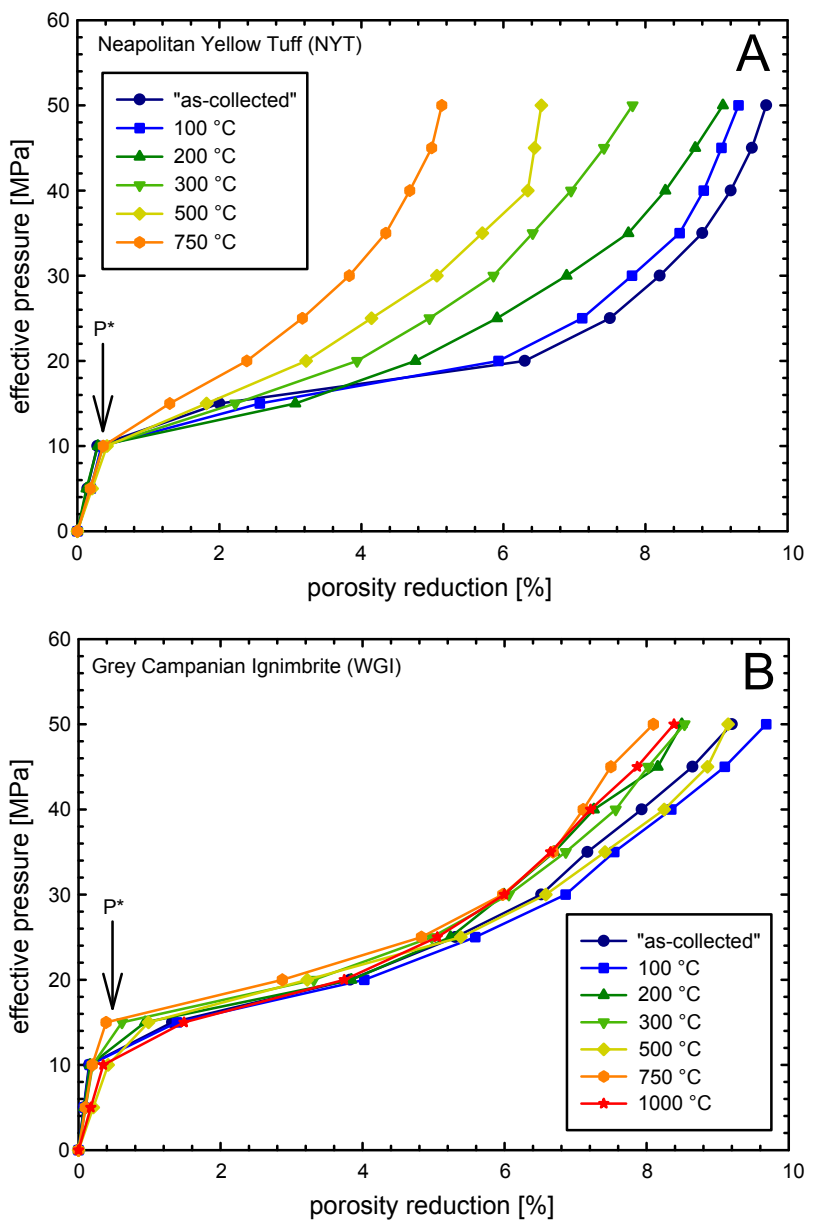

Fig. 5. The evolution of porosity change with increasing effective pressure for Neapolitan Yellow Tuff (A) and Grey Campanian Ignimbrite (B). The temperatures in the legend refer to the thermal stressing temperature (see text for details). Note that the porosity reduction on the $x$ axis is not a relative change.

where $\varepsilon_{\mathrm{r}}$ and $\varepsilon_{\mathrm{a}}$ are the radial and axial strain, respectively. Static shear modulus $\left(\mu_{\mathrm{s}}\right)$ was then calculated using the following formula (Guéguen and Palciauskas, 1994):

$\mu_{\mathrm{s}}=\frac{E_{\mathrm{s}}}{2\left(1+v_{\mathrm{s}}\right)}$.

\subsection{Microstructural analyses}

Microstructural analyses were performed using (1) the Hitachi S-3600N Environmental Scanning Electron Microscope (E-SEM) at the University of Leicester using a working distance of $14.3 \mathrm{~mm}$ and an accelerating voltage of $15 \mathrm{kV}$ and, (2) a Leica DM2500 (equipped for both transmitted and reflected light) microscope with a mounted 5 megapixel Leica DFC425 digital camera (at the Laboratoire de Déformation des Roches, Université de Strasbourg). The E-SEM was used to look for evidence of pore collapse in samples of NYT 
taken beyond $P^{*}$ (the critical pressure for the onset of inelastic compaction). Optical microscopy was used to investigate the influence of high temperatures $\left(1000^{\circ} \mathrm{C}\right)$ on the microstructure of NYT and WGI.

\section{Results}

\subsection{The evolution of porosity with increasing pressure and temperature}

Plots of the evolution of porosity with increasing Peff (commonly called "hydrostats") for both NYT and WGI at each thermal stressing temperature are displayed in Fig. 5. For porous rock, an increase in hydrostatic pressure results in a volume and porosity decrease. Initially, this compaction is elastic (i.e. recoverable) but, at some critical pressure (assuming the rock is porous enough), pore collapse and grain crushing (now non-recoverable damage) ensues and the rate of compaction accelerates. This critical pressure is denoted $P^{*}$ (Wong and Baud, 2012). The Peff required to reach $P^{*}$ varies from rock to rock, but depends largely on the initial rock porosity and grain size (generally, the higher the porosity, the lower the Peff for $P^{*}$ ). The stress at which $P^{*}$ occurs can therefore provide important information on the physical and microstructural state of rock at depth. In our experiments, the position of $P^{*}$ is about $10 \mathrm{MPa}$ for NYT (Fig. 5a) and about $10-15 \mathrm{MPa}$ for WGI (Fig. 5b). Prior to $P^{*}$, during elastic compaction, we note that the porosity change is linear (i.e. there is no concave portion that is usually attributed to the closure of microcracks; however this may be a result of the large steps in Peff between measurements). We note that there is no microstructural evidence for microcracks in the as-collected materials (see Fig. 2). Immediately following $P^{*}$, during inelastic compaction, there is a dramatic increase in the rate of porosity reduction, as inelastic compaction proceeds. However, the porosity reduction rate then gradually decreases (especially above about $20 \mathrm{MPa}$ ). This represents the hardening of the rock due to compaction. Over the entire pressure range (up to $50 \mathrm{MPa}$ ) the porosity change for the as-collected sample is about the same for NYT and WGI (between 9 and $10 \%$ ). Figure $5 \mathrm{~b}$ also shows that the porosity evolution for WGI with increasing Peff is unaffected by thermal stressing. By contrast, in the case of NYT, the porosity change decreases significantly as thermal stressing temperature increases (Fig. 5a). It can also be seen that, for both tuffs, thermal stressing does not appear to influence the position of $P^{*}$ (Fig. 5).

\subsection{The evolution of permeability with increasing pressure and temperature}

The evolution of permeability with increasing Peff for NYT and WGI at each thermal stressing temperature is displayed in Fig. 6 (the values are reported in Tables 4 and 5). Firstly, we notice that the as-collected permeabilities of the two sam-
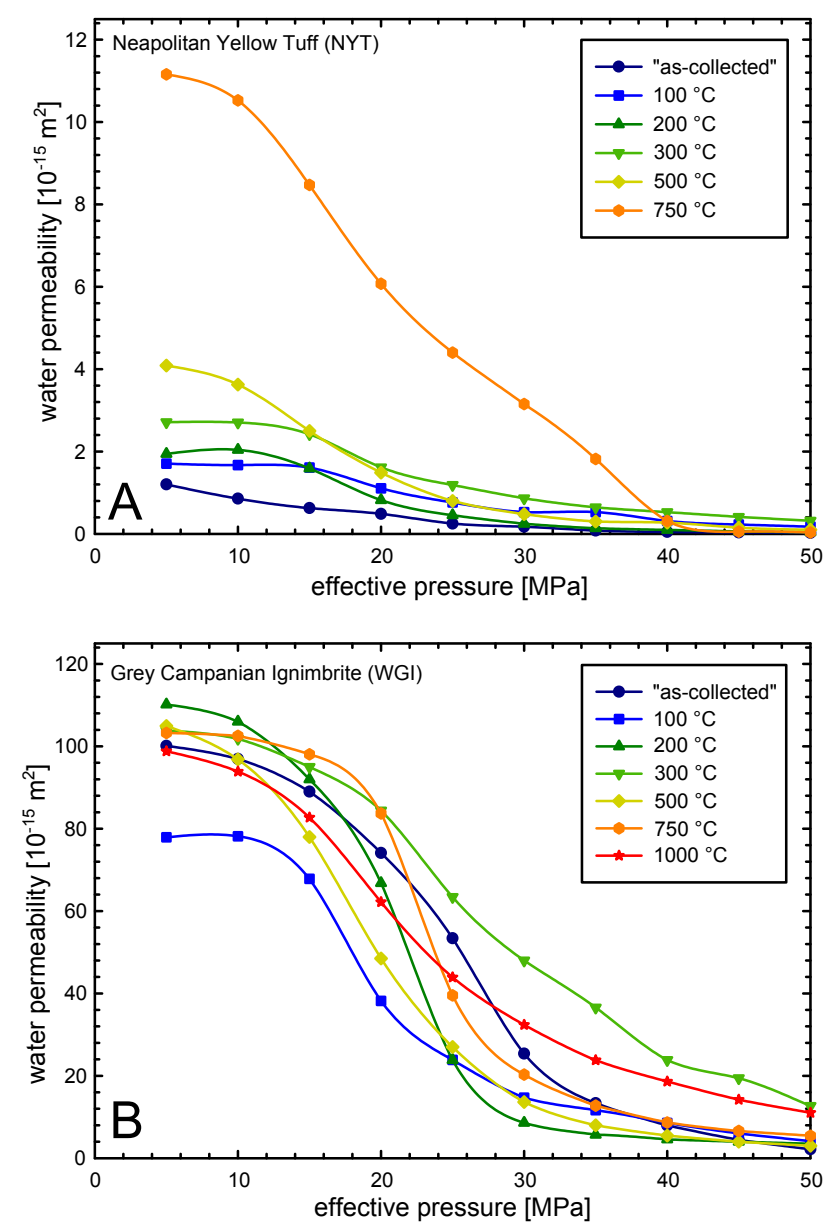

Fig. 6. The evolution of water permeability with increasing effective pressure for Neapolitan Yellow Tuff (A) and Grey Campanian Ignimbrite (B). The temperatures in the legend refer to the thermal stressing temperature (see text for details).

ples are very different. For instance, at a Peff of $5 \mathrm{MPa}$, the permeabilities are about $1.0 \times 10^{-15}$ and $1.0 \times 10^{-13} \mathrm{~m}^{2}$ for NYT (Fig. 6a) and WGI (Fig. 6b), respectively.

For WGI, the permeability curves show little change between 5 and $15 \mathrm{MPa}$ (Fig. 6b). However, above $15 \mathrm{MPa}$, the permeability starts to decrease rapidly before reaching an apparent plateau above about $30 \mathrm{MPa}$. We note that this rapid decrease starts at the same pressure as the onset of inelastic compaction $\left(P^{*}\right)$. Overall, the permeability is reduced by about an order of magnitude from $1.0 \times 10^{-13} \mathrm{~m}^{2}$ at $5 \mathrm{MPa}$ to $1.0 \times 10^{-14} \mathrm{~m}^{2}$ at $50 \mathrm{MPa}$. The permeability curves for WGI show no clear trend with increasing thermal stressing temperature (Fig. 6b). The different values obtained for the different thermal stressing temperatures are within the expected range of natural variability between different samples cored from the same block (see Table 3).

However, there is a clear influence of the thermal stressing temperature on the permeability of NYT (Fig. 6a). At a Peff 
Table 4. Water permeability of NYT as a function of effective pressure and thermal stressing temperature.

\begin{tabular}{lcccccc}
\hline \multicolumn{7}{c}{ Neapolitan Yellow Tuff (NYT) } \\
\hline $\begin{array}{l}\text { effective } \\
\text { pressure }\end{array}$ & $\begin{array}{c}\text { "as-collected" } \\
\text { permeability } \\
{[\mathrm{MPa}]}\end{array}$ & $\begin{array}{c}100^{\circ} \mathrm{C} \\
\text { permeability } \\
{\left[\mathrm{m}^{2}\right]}\end{array}$ & $\begin{array}{c}200^{\circ} \mathrm{C} \\
\text { permeability } \\
{\left[\mathrm{m}^{2}\right]}\end{array}$ & $\begin{array}{c}300^{\circ} \mathrm{C} \\
\text { permeability } \\
{\left[\mathrm{m}^{2}\right]}\end{array}$ & $\begin{array}{c}500^{\circ} \mathrm{C} \\
\text { permeability } \\
{\left[\mathrm{m}^{2}\right]}\end{array}$ & $\begin{array}{c}750^{\circ} \mathrm{C} \\
\text { permeability } \\
{\left[\mathrm{m}^{2}\right]}\end{array}$ \\
\hline 5 & $1.2 \times 10^{-15}$ & $1.7 \times 10^{-15}$ & $1.9 \times 10^{-15}$ & $2.7 \times 10^{-15}$ & $4.1 \times 10^{-15}$ & $1.1 \times 10^{-14}$ \\
10 & $8.5 \times 10^{-16}$ & $1.7 \times 10^{-15}$ & $2.0 \times 10^{-15}$ & $2.7 \times 10^{-15}$ & $3.6 \times 10^{-15}$ & $1.1 \times 10^{-14}$ \\
15 & $6.3 \times 10^{-16}$ & $1.6 \times 10^{-15}$ & $1.6 \times 10^{-15}$ & $2.4 \times 10^{-15}$ & $2.5 \times 10^{-15}$ & $8.5 \times 10^{-15}$ \\
20 & $4.9 \times 10^{-16}$ & $1.1 \times 10^{-15}$ & $8.2 \times 10^{-16}$ & $1.6 \times 10^{-15}$ & $1.5 \times 10^{-15}$ & $6.1 \times 10^{-15}$ \\
25 & $2.5 \times 10^{-16}$ & $7.6 \times 10^{-16}$ & $4.5 \times 10^{-16}$ & $1.2 \times 10^{-15}$ & $8.0 \times 10^{-16}$ & $4.4 \times 10^{-15}$ \\
30 & $1.7 \times 10^{-16}$ & $5.3 \times 10^{-16}$ & $2.5 \times 10^{-16}$ & $8.6 \times 10^{-16}$ & $4.8 \times 10^{-16}$ & $3.2 \times 10^{-15}$ \\
35 & $8.0 \times 10^{-17}$ & $5.3 \times 10^{-16}$ & $1.4 \times 10^{-16}$ & $6.4 \times 10^{-16}$ & $3.0 \times 10^{-16}$ & $1.8 \times 10^{-15}$ \\
40 & $4.7 \times 10^{-17}$ & $3.1 \times 10^{-16}$ & $9.6 \times 10^{-17}$ & $5.3 \times 10^{-16}$ & $2.7 \times 10^{-16}$ & $3.1 \times 10^{-16}$ \\
45 & $3.5 \times 10^{-17}$ & $2.3 \times 10^{-16}$ & $6.0 \times 10^{-17}$ & $4.1 \times 10^{-16}$ & $1.5 \times 10^{-16}$ & $5.4 \times 10^{-17}$ \\
50 & $2.4 \times 10^{-17}$ & $1.7 \times 10^{-16}$ & $4.0 \times 10^{-17}$ & $3.2 \times 10^{-16}$ & $1.0 \times 10^{-16}$ & $3.3 \times 10^{-17}$
\end{tabular}

Table 5. Water permeability of WGI as a function of effective pressure and thermal stressing temperature.

\begin{tabular}{lllllll}
\hline & \multicolumn{5}{l}{ Grey Campanian Ignimbrite (WGI) } \\
\hline $\begin{array}{l}\text { effective } \\
\text { pressure } \\
{[\mathrm{MPa}]}\end{array}$ & $\begin{array}{l}\text { "as-collected" } \\
\text { permeability } \\
{\left[\mathrm{m}^{2}\right]}\end{array}$ & $\begin{array}{l}100^{\circ} \mathrm{C} \\
\text { permeability } \\
{\left[\mathrm{m}^{2}\right]}\end{array}$ & $\begin{array}{l}200^{\circ} \mathrm{C} \\
\text { permeability } \\
{\left[\mathrm{m}^{2}\right]}\end{array}$ & $\begin{array}{l}300^{\circ} \mathrm{C} \\
\text { permeability } \\
{\left[\mathrm{m}^{2}\right]}\end{array}$ & $\begin{array}{l}500^{\circ} \mathrm{C} \\
\text { permeability } \\
{\left[\mathrm{m}^{2}\right]}\end{array}$ & $\begin{array}{l}750^{\circ} \mathrm{C} \\
\text { permeability } \\
{\left[\mathrm{m}^{2}\right]}\end{array}$
\end{tabular}

of $5 \mathrm{MPa}$, the permeability increases from $1.0 \times 10^{-15} \mathrm{~m}^{2}$ for the as-collected sample to $1.1 \times 10^{-14} \mathrm{~m}^{2}$ for the sample thermally stressed to $750{ }^{\circ} \mathrm{C}$, an increase of an order of magnitude. As for the WGI, the permeability curves show little change between 5 and $10 \mathrm{MPa}$, after which permeability decreases more rapidly. We again note that this rapid decrease starts at the same pressure as the onset of inelastic compaction $\left(P^{*}\right)$. Over the entire pressure range, the permeability is reduced by about an order of magnitude for the ascollected sample and by about three orders of magnitude for the sample thermally stressed to $750{ }^{\circ} \mathrm{C}$ (the total decrease in permeability increases with increasing thermal stressing temperature, Fig. 6a). The permeability curves all converge at about $40 \mathrm{MPa}$ (at a permeability of about $4.0 \times 10^{-17} \mathrm{~m}^{2}$ ). Therefore, at Peffs of $40 \mathrm{MPa}$ and above, there is no longer any influence of thermal stressing on the permeability of NYT.

\subsection{The evolution of ultrasonic velocities and dynamic elastic moduli with increasing pressure and temperature}

The evolution of the physical properties (ultrasonic wave velocities, dynamic elastic moduli, and $V_{P} / V_{S}$ ratio) for NYT and WGI are shown in Figs. 7 and 8, respectively. Firstly, it can be remarked that the as-collected physical properties of the two tuffs are similar (see also Table 1). For both tuffs, $P$ and $S$ wave velocity (Figs. 7a, b; 8a, b), dynamic Young's modulus (Figs. 7c, 8c), dynamic Poisson's ratio (Figs. 7d, 8d), dynamic shear modulus (Figs. $7 \mathrm{e}, 8 \mathrm{e}$ ), and $V_{P} / V_{S}$ ratio (Figs. 7f, 8f) all increase with increasing Peff, and in a similar manner. For example, for the as-collected NYT sample, $P$ wave velocity increases by $40 \%$ (Fig. 7a), $S$ wave velocity by $21 \%$ (Fig. 7b), Young's modulus by $53 \%$ (Fig. 7c), Poisson's ratio by $19 \%$ (Fig. 7d), shear modulus by $47 \%$ (Fig. 7e), and $V_{P} / V_{S}$ ratio by $15 \%$ (Fig. $7 \mathrm{f}$ ) over the entire pressure range $(5-50 \mathrm{MPa})$. The relative increases are 

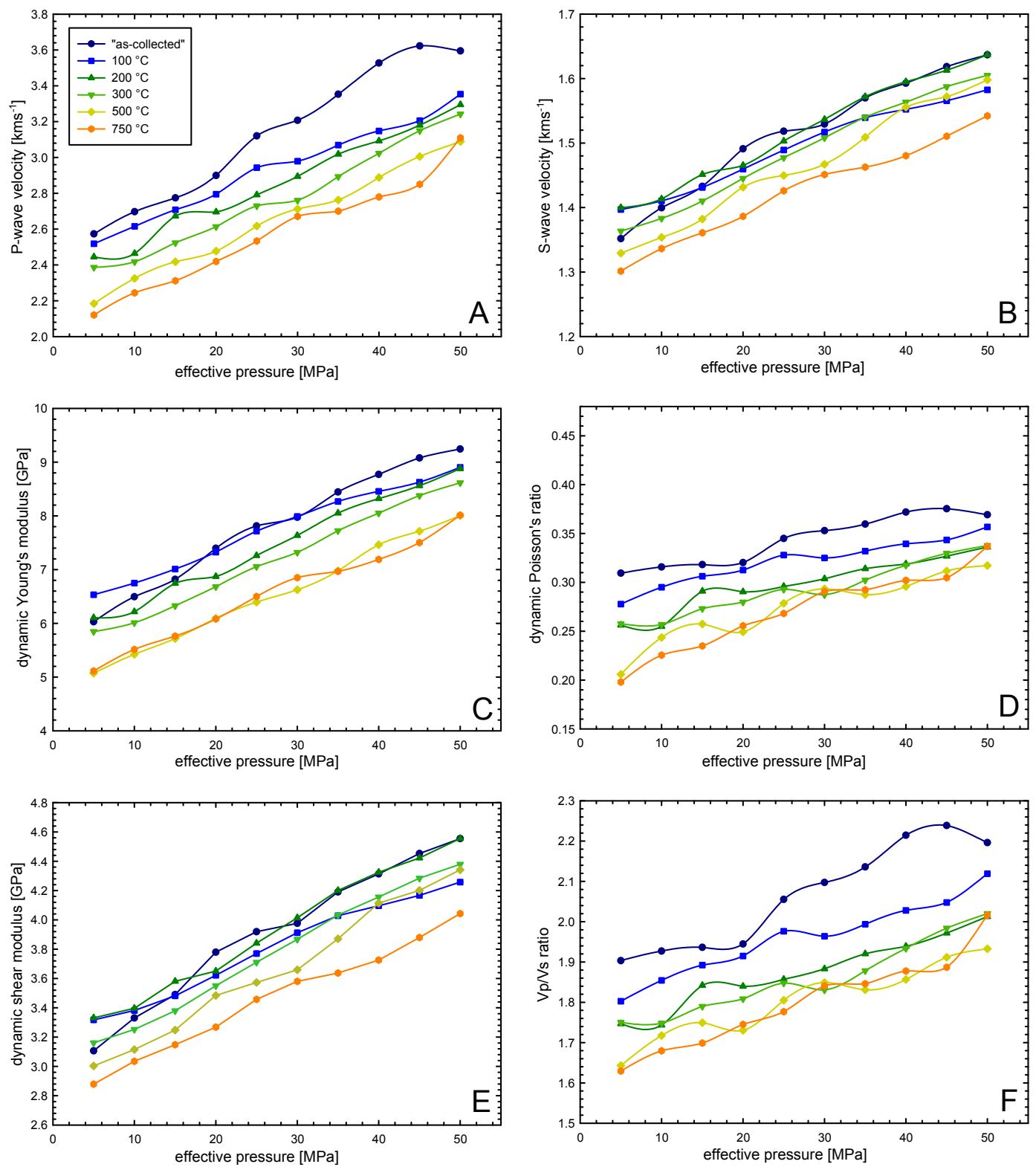

Fig. 7. The evolution of $P$ wave velocity (A), $S$ wave velocity (B), dynamic Young's modulus (C), dynamic Poisson's ratio (D), dynamic shear modulus (E), and $V_{P} / V_{S}$ ratio (F) with increasing effective pressure for Neapolitan Yellow Tuff. The temperatures in the legend refer to the thermal stressing temperature (see text for details).

similar for both tuffs. However, whereas the results for NYT (Fig. 7) show a systematic decrease in all the physical properties with increasing thermal stressing temperature, no systematic pattern can be discerned in the WGI results (Fig. 8). At a constant Peff, thermal stressing decreases $P$ and $S$ wave velocity, dynamic Young's modulus, dynamic Poisson's ratio, and $V_{P} / V_{S}$ ratio in NYT. For example, for NYT at a Peff of $5 \mathrm{MPa}, P$ wave velocity decreases by $21 \%$ (Fig. 7a), $S$ wave velocity by $4 \%$ (Fig. 7b), Young's modulus by $18 \%$ (Fig. 7c), Poisson's ratio by $56 \%$ (Fig. 7d), shear modulus by $8 \%$ (Fig. 7 e), and $V_{P} / V_{S}$ ratio by $17 \%$ (Fig. 7 f) over the entire temperature range (as-collected to $750^{\circ} \mathrm{C}$ ).

\subsection{Static elastic moduli under triaxial conditions}

The differential stress-axial strain curves and associated AE energy output curves for the triaxial experiments are shown in Fig. 9, and the differential stress-porosity reduction curves are shown in Fig. 10. Even at a Peff as low as $5 \mathrm{MPa}$, the deformation behaviour of the two tuffs can be described as macroscopically ductile (i.e. their ability to resist load did not decrease, see Rutter, 1986). For both rocks, a critical 

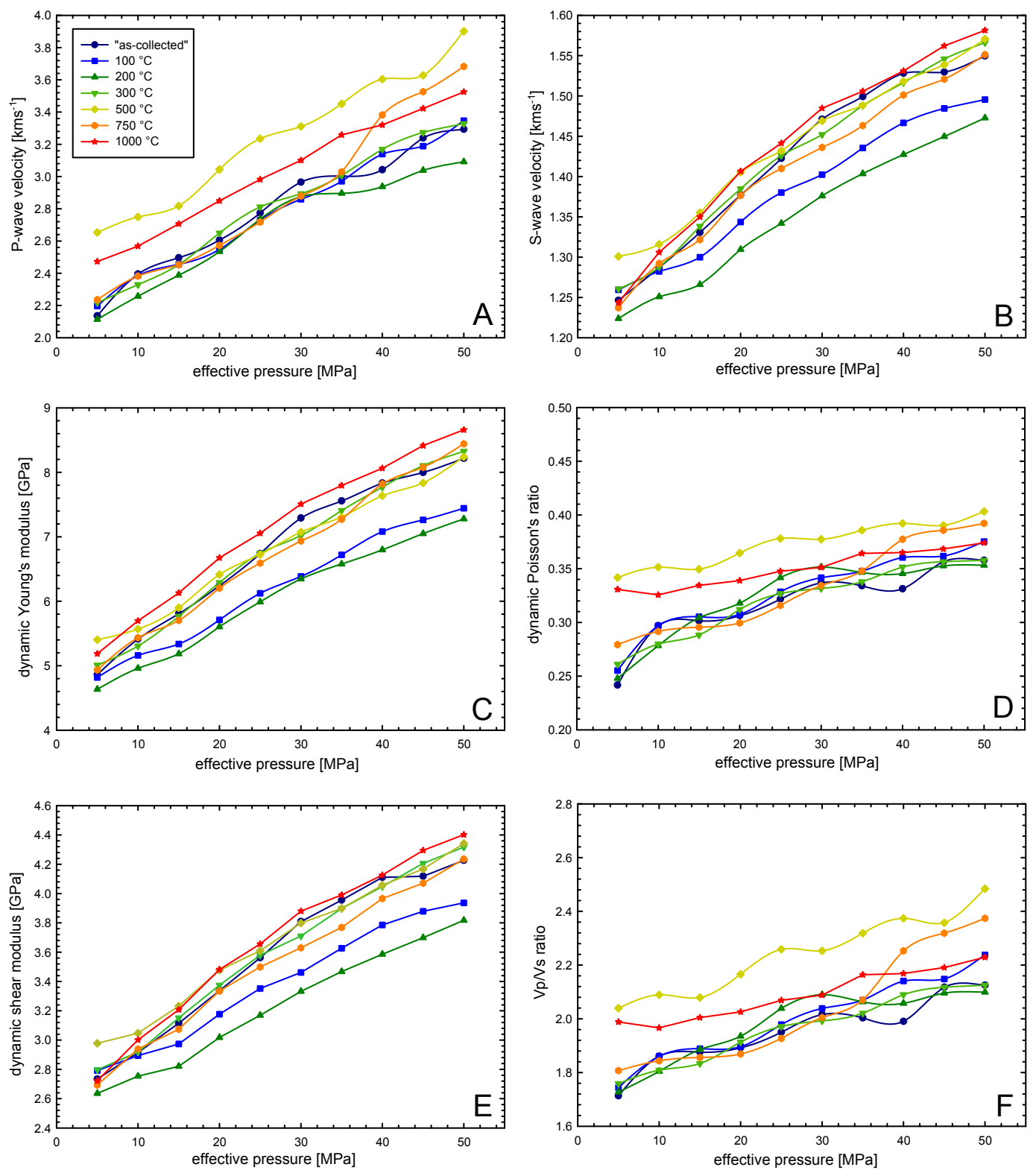

Fig. 8. The evolution of $P$ wave velocity (A), $S$ wave velocity (B), dynamic Young's modulus (C), dynamic Poisson's ratio (D), dynamic shear modulus $(\mathbf{E})$, and $V_{P} / V_{S}$ ratio $(\mathbf{F})$ with increasing effective pressure for Grey Campanian Ignimbrite. The temperatures in the legend refer to the thermal stressing temperature (see text for details).

pressure, termed $C^{*}$ (Wong and Baud, 2012), is reached and marks the point where there is an acceleration in axial strain (Fig. 9) and porosity reduction (or volumetric strain, Fig. 10) for a given stress increment. This phenomenon is called "shear-enhanced compaction", and beyond $C^{*}$ the rocks are deforming in the compactive, cataclastic flow regime which, in this case, is associated with strain hardening. In our experiments, $C^{*}$ occurs at differential stresses of about 4 and $7 \mathrm{MPa}$ for NYT (Figs. 9a, 10a) and WGI (Figs. 9b, 10b), respectively. This contrasts with the values for $P^{*}$ of 10 and $15 \mathrm{MPa}$, respectively, and demonstrates how the appli- cation of shear stresses enhances compactive deformation. Although this mode of failure differs greatly from the brittle failure seen in the uniaxial experiments of Heap et al. (2012) on the same rocks, both deformation mechanisms involve the same micromechanical process: microcracking (as evidenced by the output of AE energy; a proxy for microcracking). However, whereas strain localization is seen in the brittle field, cataclastic flow involves distributed microcracking (i.e. localization does not occur). Indeed, we see no evidence for strain localization in the post-experimental samples. The output of AE energy is seen to increase in a somewhat stepwise 

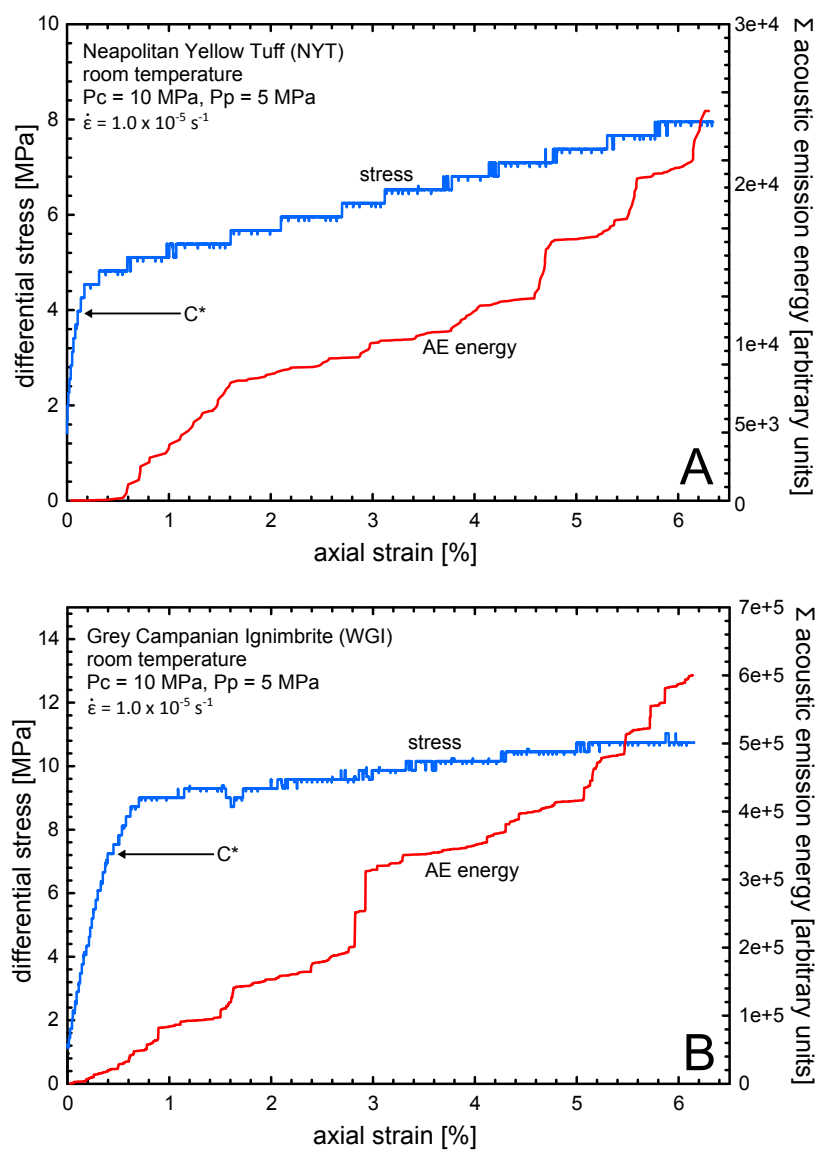

Fig. 9. Constant strain rate stress-strain curves, together with the cumulative output of AE "energy" (the area under the received AE waveform envelope) for as-collected Neapolitan Yellow Tuff (A) and Grey Campanian Ignimbrite (B). The experimental conditions are provided on each panel and the positions of $C^{*}$ are indicated by the arrows. The steps in the data are due to the stepwise nature of the pumps.

manner for both rocks (Fig. 9), reflecting bursts of microcracking events during deformation, we note that the average rate of AE energy output for WGI is some 20 times higher than for NYT. The difference in AE energy output during deformation is likely to be the result of the compositional differences between the two tuffs.

Values for the static Young's modulus, static Poisson's ratio, and static shear modulus were calculated from the elastic portions of the stress-strain curves and are given in Table 6, together with dynamic values determined at the same pressure $(\mathrm{Peff}=5 \mathrm{MPa})$ for comparison. We note that both the static Young's modulus and the static shear modulus are significantly lower than the corresponding dynamic values.
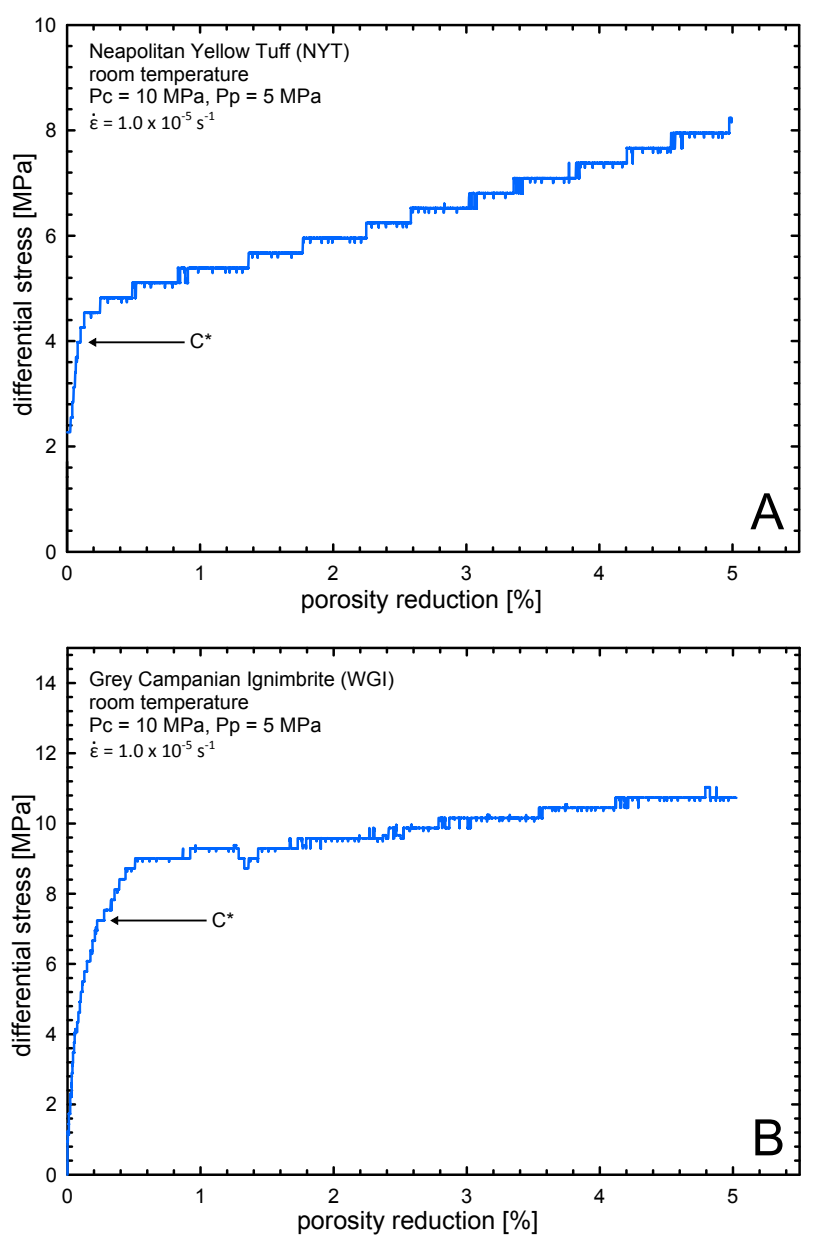

Fig. 10. Constant strain rate stress-porosity reduction curves for as-collected Neapolitan Yellow Tuff (A) and Grey Campanian Ignimbrite (B). The experiments shown here are the same as those in Fig. 9. The experimental conditions are provided on each panel and the positions of $C^{*}$ are indicated by the arrows. The steps in the data are due to the stepwise nature of the pumps. Note that the porosity reduction on the $x$ axis is not a relative change.

\section{Discussion}

\subsection{Fluid flow and physical property evolution with depth}

Our experimental data show that the water permeability of different as-collected tuff samples from Campi Flegrei can vary by multiple orders of magnitude (at a Peff of $5 \mathrm{MPa}$, permeabilities are $1.0 \times 10^{-15}$ and $1.0 \times 10^{-13} \mathrm{~m}^{2}$ for NYT and WGI, respectively). This difference in permeability could be considered surprising if one were to solely consider their connected porosities (44 and $49 \%$ for NYT and WGI, respectively). The difference in permeability is likely due to differences in pore space connectivity, perhaps related to the extent of zeolitization and lithification. A similar conclusion was drawn by Vinciguerra et al. (2009). Vinciguerra et 

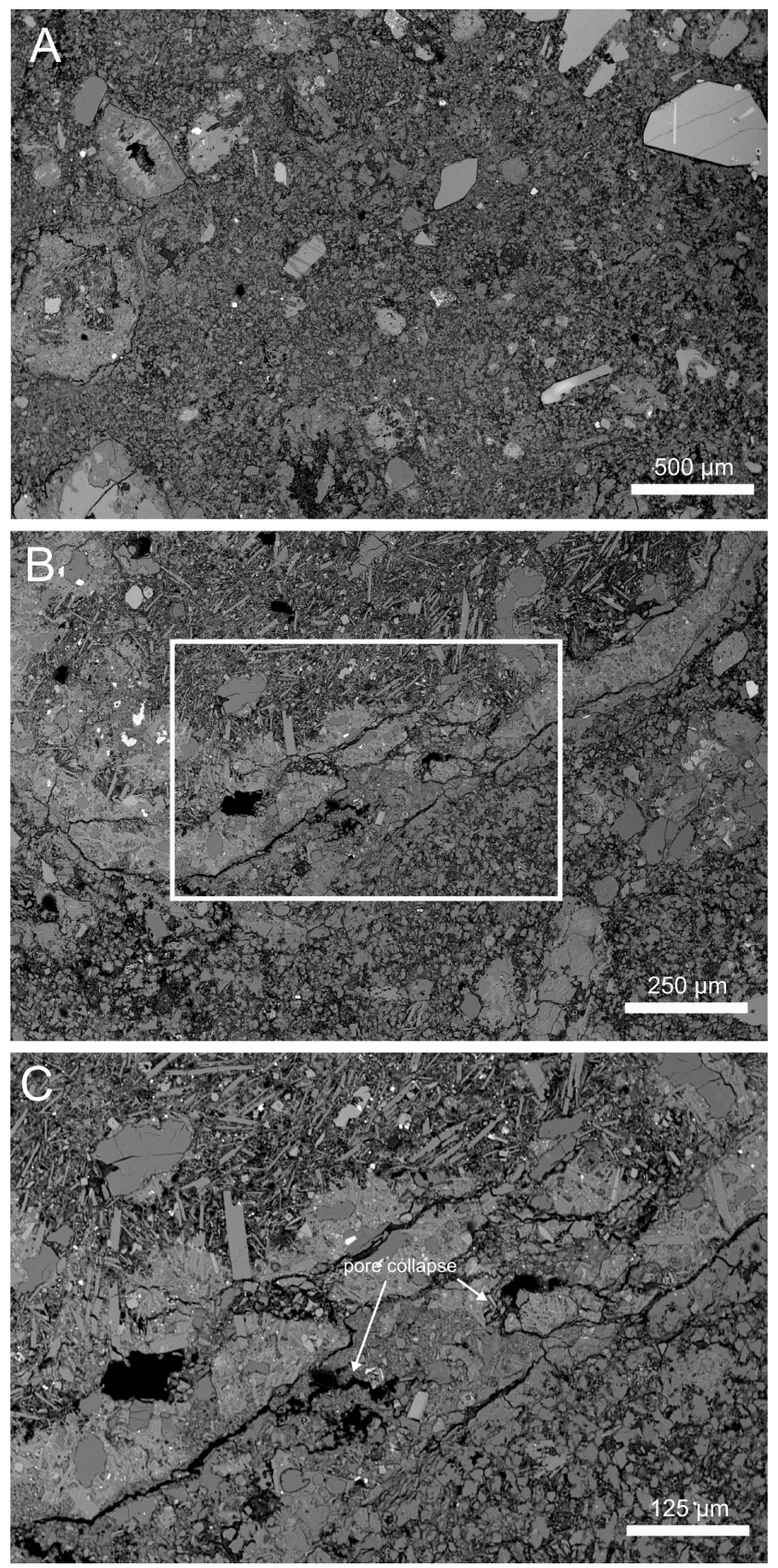

Fig. 11. Scanning electron microscope images of an as-collected sample of Neapolitan Yellow Tuff taken beyond $P^{*}$. (A) shows an overview of the post- $P^{*}$ microstructure at a low magnification. (B) and $(\mathbf{C})$ show detailed evidence of pore collapse (indicated by the white arrows). (C) is a zoom of the white box shown in $(\mathbf{B})$.

al. (2009) measured the permeability of two different tuffs from the Alban Hills (Italy) and found that, at a Peff of $5 \mathrm{MPa}$, the permeabilities of the two tuffs were significantly different. While the first (well-lithified, zeolitized facies with an average porosity of $14 \%$ ) was found to have a permeability of about $10^{-18} \mathrm{~m}^{2}$, which decreased by about an order of magnitude upon the application of a Peff of $70 \mathrm{MPa}$, the
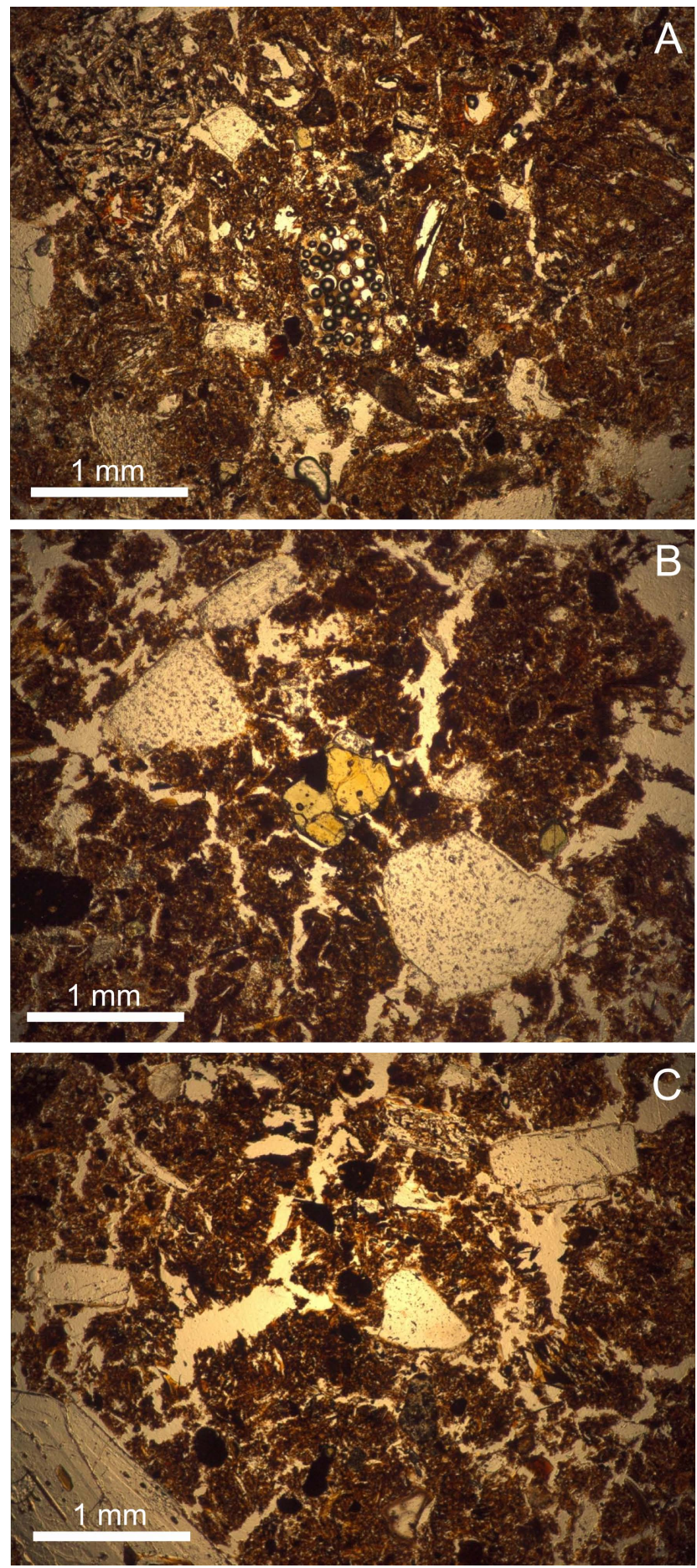

Fig. 12. Optical microscope images of Neapolitan Yellow Tuff thermally stressed to a temperature of $1000^{\circ} \mathrm{C}$ showing macrocracks. The photomicrograph in panel A, showing foaming, is taken from Heap et al. (2012).

second (fine-grained, matrix-supported facies with frequent centimetre-sized accretionary lapilli and an average porosity of $18 \%$ ) had a much higher permeability (about $10^{-15} \mathrm{~m}^{2}$ ) 

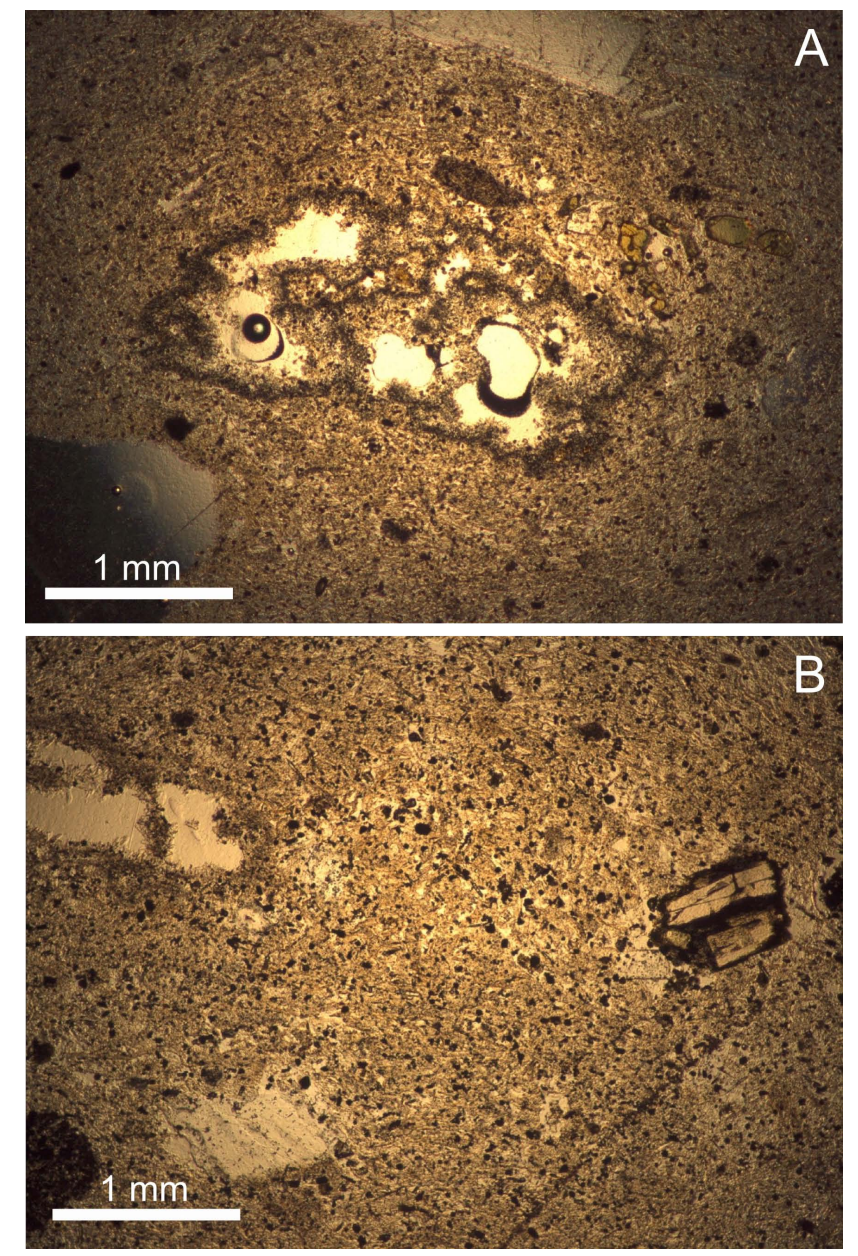

Fig. 13. Optical microscope images of Grey Campanian Ignimbrite thermally stressed to a temperature of $1000^{\circ} \mathrm{C}$. Both photographs are taken from Heap et al. (2012).

that decreased by about two orders of magnitude over the same pressure range. Further, considering the high porosities of NYT and WGI, their permeabilities are actually surprisingly low; considered to be a consequence of their complex pore structure. By contrast, Boise sandstone (porosity of $35 \%$ ), a rock with a much simpler microstructure, has a permeability of $1.8 \times 10^{-12} \mathrm{~m}^{2}$ at a Peff of $5 \mathrm{MPa}$ (Zhu and Wong, 1997).

Our experimental data also show that the permeability of the two tuffs is reduced by about an order of magnitude over the pressure range from 5 to $50 \mathrm{MPa}$. In detail, the reduction in permeability with increasing Peff is modest up to a Peff of about $10-15 \mathrm{MPa}$, and accelerates at pressures above 10$15 \mathrm{MPa}$. This can be explained by the position of $P^{*}$ (Fig. 5), the onset of inelastic pore collapse and grain crushing. As pores collapse and grains are crushed, the pathways for fluid flow are obstructed. This inelastic compaction also has a significant influence on other physical properties of the tuffs (ultrasonic wave velocities, dynamic elastic moduli, and the
$V_{P} / V_{S}$ ratio all increase), in agreement with similar studies on NYT (Vanorio et al., 2002; Vinciguerra et al., 2006). Evidence of pore collapse is illustrated in the E-SEM image of a sample of NYT taken beyond $P^{*}$ provided as Fig. 11. Pore collapse above $P^{*}$ has previously been observed in a tuff from the Alban Hills, Italy (Zhu et al., 2011). A pressure of about 10-15 MPa roughly equates to a depth of about $750 \mathrm{~m}$. Geological cross sections of CF (e.g. Orsi et al., 1996) suggest therefore that a large volume of the NYT and WGI tuffs are located at depths where the pressure will be above $P^{*}$. This conjecture is confirmed by the reduced porosity of samples taken from borehole samples (see the report by Giberti et al., 2006). Measurements on borehole samples from San Vito 1 (at the periphery of the inferred caldera) showed that the porosity decreases from $40.5 \%$ at the surface to 32.9 , $21.9,21.9$, and $15.1 \%$ at depths of $810,1420,2130$, and $2860 \mathrm{~m}$, respectively. Our data show that the porosity loss for NYT at $2860 \mathrm{~m}$ will be about $9 \%$. A starting porosity of $44 \%$ yields a porosity, purely due to mechanical compaction, of $35 \%$ at a depth of $2860 \mathrm{~m}$. This would imply a porosity loss due to chemical alteration of about $20 \%$ and suggests that the impact of hot, circulating fluids plays the dominant role in the porosity loss of these pyroclastic deposits at depth. Indeed, the report by Giberti et al. (2006) suggests that it is the presence of clay minerals, rather than compaction, that is responsible for the major changes in porosity with depth.

We are certainly aware that our permeability data were collected on rocks from open quarries and, although their properties were measured at the relevant pressures (and under a range of thermal stressing temperatures), may not therefore accurately represent the material at depth (which have had time to compact, lithify, undergo chemical alteration; e.g. see de Gennaro et al., 2000). However, the open access report of Giberti et al. (2006) offers some permeability data on borehole samples. Data from borehole samples taken from San Vito 1 (at the periphery of the inferred caldera) show that, as the porosity is reduced to $32.9,21.9,21.9$, and $15.1 \%$ at depths of $810,1420,2130$, and $2860 \mathrm{~m}$, respectively, the permeability (Klinkenberg corrected gas permeabilities) of the samples are $1.1 \times 10^{-13}, 2.5 \times 10^{-16}, 7.9 \times 10^{-16}$, and $4.9 \times 10^{-16} \mathrm{~m}^{2}$, respectively. The permeability of the quarry samples of this study are $8.0 \times 10^{-17} \mathrm{~m}^{2}$ at a depth of about $2860 \mathrm{~m}$. From these data it is clear that there is no simple relationship between the mechanical compaction and chemical alteration that afflicted the samples at depth (causing a substantial porosity loss) and their permeability.

\subsection{The influence of temperature on fluid flow and physical properties}

Our experimental data show that thermal stressing has a strong influence on the physical properties of NYT, whereas those for WGI are unaffected. The fluid flow properties of NYT are enhanced (especially at shallow depths) upon exposure to high temperatures, and the ultrasonic wave velocities, 
dynamic elastic moduli, and the $V_{P} / V_{S}$ ratio decrease. Thermal stressing has previously shown to decrease ultrasonic wave velocities in a zeolitized tuff from CF (Vinciguerra et al., 2006). The marked difference in the temperature dependence of the physical properties between the two tuffs is likely due to the presence of significant quantities of thermally unstable zeolites in NYT, namely phillipsite and chabazite, which are not present in WGI (Heap et al., 2012). Heap et al. (2012) showed, using a combination of thermogravimetric analysis, optical microscopy, and X-ray diffraction, that NYT lost $18 \%$ of its initial mass, contained large numbers of macrocracks, and no longer contained any zeolites after exposure to $1000^{\circ} \mathrm{C}$. By contrast, no changes in mass, microstructure, or chemistry were seen in WGI heated to the same temperature (Heap et al., 2012). Optical microscope photomicrographs of NYT and WGI thermally stressed to a temperature of $1000^{\circ} \mathrm{C}$ are provided as Figs. 12 and 13, respectively. Figure 12 shows that the microstructure of NYT is very different to that depicted in Fig. $2 b$ for the as-collected material. Many cracks are present (Fig. 12a-c) and some areas contain $1 \mathrm{~mm}$ wide foamed glass (Fig. 12a). By contrast, the microstructure of WGI, upon exposure to $1000^{\circ} \mathrm{C}$ (Fig. 13), is indistinguishable from the as-collected microstructure shown in Fig. 2d. These observations have been previously reported in Heap et al. (2012). Since, phillipsite and chabazite represent the "cement" that promoted the lithification of the originally incoherent pozzolanic material constituting NYT (de Gennaro et al., 2000), the structural integrity of NYT deteriorates significantly upon their loss (Heap et al., 2012). Detailed studies (de Gennaro and Colella, 1989, and references therein) on the thermal decomposition of the zeolites in NYT have highlighted that analcime loses water irreversibly, and that chabazite and phillipsite undergo a partial reversible dehydration at $240^{\circ} \mathrm{C}$. Phillipsite breaks down during dehydration and chabazite undergoes reversible hydration at $350{ }^{\circ} \mathrm{C}$, and, by $900^{\circ} \mathrm{C}$, the structure of the zeolites will be so damaged that no further water molecules can be stored (see de Gennaro and Colella, 1989, and references therein). Therefore, the reported changes in NYT physical properties are due to a combination of thermal cracking and the cracks formed as a result of the disintegration of the material through the loss of zeolites.

If we consider NYT at a depth of $1 \mathrm{~km}$, the geothermal gradients provided by the AGIP (1987) exploration boreholes show that temperatures of $200-250^{\circ} \mathrm{C}$ are not unreasonable (Wohletz et al., 1999; de Lorenzo et al., 2001). The data of this study reveal that the zeolitized NYT are prone to undesirable thermal alteration at these temperatures. At temperatures of $200-250{ }^{\circ} \mathrm{C}$, permeability increases by a factor of 2.5 , ultrasonic wave velocities, dynamic elastic moduli, and $V_{P} / V_{S}$ ratio decrease by roughly $10 \%$; and uniaxial compressive strength and indirect tensile strength are reduced by more than a factor of 2 (Heap et al., 2012). A reduction in tensile strength may further promote physical property changes by encouraging fluid pressure driven fracturing. An internal pore fluid pressure of $22-23 \mathrm{MPa}$ (under a confining pressure of 6-7 MPa) was sufficient to fracture a sandstone of $13 \%$ porosity (Vinciguerra et al., 2004). It is therefore likely that the estimated overpressures needed to explain the ground deformation at CF (e.g. $10 \mathrm{MPa}$, Gaeta et al., 1998) are sufficient to fracture the tuffs and cause further changes in rock physical properties. Although it has been shown that the porosity of borehole samples can be much less than those collected from the surface (see the report of Giberti et al., 2006), perhaps, given their complex microstructure, it is unwise to assume that these rocks are stronger. To understand whether fluid driven fracturing is prevalent at $\mathrm{CF}$, measurements of the tensile strength of samples taken from boreholes is required.

\subsection{Application of these data to ground deformation modelling at $\mathbf{C F}$}

Our data highlight that the elastic moduli of two different tuffs from CF are significantly depth-dependent (Figs. 7, 8). The implication of these data is that the assumption of a homogenous half-space may be an oversimplification, and is exacerbated further when one considers the extent of the variability of the tuffs within the caldera (which are variably lithified, altered, and zeolitized, see the report of Giberti et al., 2006). These data highlight the need for the development of more complex, multi-layer ground deformation models. In order to assess the extent of the variability in elastic moduli of the rocks within the caldera at $\mathrm{CF}$, a systematic experimental approach involving borehole samples from different depths and locations within the caldera is now required (discussed further at the end of the section).

We also find that static and dynamic moduli for the same tuff differ substantially. Although it is not uncommon for static and dynamic elastic moduli to be different, due to their frequency-dependence (Simmons and Brace, 1965; Cheng and Johnston, 1981; Eissa and Kazi, 1989; Ciccotti and Mulargia, 2004; Ciccotti et al., 2004), it raises an important question regarding which values are more appropriate in modelling. Manconi et al. (2010) highlighted that, while dynamic elastic constants (those derived from seismic velocities) are representative for rock subject to a dynamic stress, perhaps static values are more appropriate in the analysis of deformation caused by volcanic sources. A similar conclusion was drawn by Heap et al. (2009). However, static elastic moduli for representative rocks at CF have not been available until now. Thus far, elastic moduli have been generally assumed, or extrapolated from seismic tomography studies (e.g. Chiarabba and Moretti, 2006). Typically, Poisson's ratio is taken as 0.3 and shear modulus as $5 \mathrm{GPa}$ (e.g. De Natale et al., 1991). However, while our data show that static and dynamic Poisson's ratio is similar for the measured tuffs (and equal to about 0.3 ; measurements on borehole samples are also consistently about 0.3 , see the report by Giberti et al., 2006), we also observe that the static shear modulus is about 
Table 6. The static and dynamic elastic moduli of NYT and WGI measured under an effective pressure of $5 \mathrm{MPa}$.

\begin{tabular}{lcccc}
\hline & \multicolumn{2}{c}{ Neapolitan Yellow Tuff (NYT) } & \multicolumn{2}{c}{ Grey Campanian Ignimbrite (WGI) } \\
\cline { 2 - 5 } & static & dynamic & static & dynamic \\
Young's modulus [GPa] & 2.1 & 6.0 & 1.7 & 4.9 \\
Poisson's ratio & 0.30 & 0.31 & 0.29 & 0.24 \\
shear modulus [GPa] & 0.81 & 3.1 & 0.66 & 2.7 \\
\hline
\end{tabular}

a factor of four lower than the dynamic value (Table 6). If one were to assume that our static values are representative, then a more suitable shear modulus would be $0.5 \mathrm{GPa}$, an order of magnitude lower than the values typically used in ground deformation modelling at CF. We note that, while values of the shear modulus of borehole samples provided in the report of Giberti et al. (2006) show that the dynamic shear modulus can reach values of $10.9 \mathrm{GPa}$ at a depth of $2860 \mathrm{~m}$, no complementary static values exist. Future research should focus on the determination of the static elastic moduli of borehole samples.

To date, the values of permeability used in the numerous thermodynamical and magmatic-hydrothermal models have spanned many orders of magnitude. For example, Gaeta et al. (1998) use a value of $10^{-11} \mathrm{~m}^{2}$, inferred from the measurements of Ascolese et al. (1993a, b) and De Natale et al. (2001) use the same value, but inferred from the in situ observations of Rosi and Sbrana (1987). By contrast, Gaeta et al. (2003) use a much lower value of $10^{-15} \mathrm{~m}^{2}$, taken from the ambient pressure measurements of Peluso and Arienzo (2007). The experimental data of this study has shown that (1) the permeability of tuffs at CF can differ by about 1.5 orders of magnitude (from $2.0 \times 10^{-15}$ to $6.3 \times 10^{-17} \mathrm{~m}^{2}$, due to the extent of zeolitization and lithification, see Tables 4 and 5), (2) effective pressure (depth) can significantly alter the permeability of tuff (by up to 2 orders of magnitude, see Fig. 6) and, (3) if the tuff is zeolitized, permeability can be increased by thermal stressing episodes (Fig. 6a). While we note that the permeability of different tuffs at CF can differ greatly (we expect the extent of the variation to greatly exceed the 1.5 orders of magnitude quoted here), the same will also be true for tuff from the same eruptive episode. The NYT and the Campanian Ignimbrite - both thick and widespread pyroclastic deposits - are well known to be variably lithified and zeolitized (de Gennaro et al., 2000; Langella et al., 2013). The highly variable nature of tuffs at $\mathrm{CF}$ (both laterally and vertically, see the report by Giberti et al., 2006), coupled with the depth-dependence of permeability, is likely to produce highly variable permeabilities within the caldera. Unfortunately, the implication of this conclusion is that, to accurately model ground deformation using a model that requires an estimation of the permeability of the materials within the caldera, we now require (1) permeability measurements on borehole samples (from different depths and different locations within the caldera) to assess the extent of the variability in permeability within the caldera and, (2) the development of more complex models that can account for such variations in permeability.

To conclude, while we advise that our laboratory-derived values should be considered for routine ground deformation modelling at $\mathrm{CF}$, we also urge caution. Firstly, our measurements on laboratory-sized samples do not account for large faults or fractures, which, for example, would serve to lower Young's modulus. Secondly, an important question arises: what constitutes "representative" materials for the caldera at CF? Although our experiments were conducted (1) on samples from the two most widespread tuff lithologies that comprise CF, (2) under the relevant pressures or depths, (3) on water-saturated samples and, (4) over a range of thermal stressing temperatures, our samples were collected from an open quarry and may therefore not represent the material at depth (which have had time to compact, lithify, undergo chemical alteration; e.g. see de Gennaro et al., 2000; see also the report by Giberti et al., 2006). However, we highlight that the permeability measurements on borehole samples presented in the report of Giberti et al. (2006) suggest that (1) the permeability measurements of this study are not dissimilar to those measured on borehole samples and, (2) there is clearly no simple relationship between porosity and permeability. Further, the tuffs of CF are likely to be extremely variable (due to variable lithification, zeolitization, interaction with fluids and temperatures) laterally (i.e. within the same lithological unit) and therefore their physical properties at a constant depth are also likely to span a wide range. It is clear that systematic measurements on deep scientific borehole samples are now needed from multiple locations and depths within the caldera to assess the extent of the variability in static elastic moduli and permeability of the rocks that form the caldera. To conclude, we anticipate that no unique values of permeability or elastic moduli exist for the materials within $\mathrm{CF}$, highlighting the need for the development of more complex ground deformation models.

\section{Conclusions}

1. Our experimental data show that the permeabilities of tuffs from Campi Flegrei (the Neapolitan Yellow Tuff and a tuff from the Campanian Ignimbrite) can vary by multiple orders of magnitude. Despite this, our data also show that their elastic moduli are similar; 
however, we note that dynamic and static moduli differ greatly. These data emphasize the heterogeneous nature of the tuffs that comprise the caldera at Campi Flegrei.

2. Increasing the effective pressure from 5 to $50 \mathrm{MPa}$ results in a permeability reduction of about an order of magnitude and a porosity reduction between 5 and $10 \%$ for both tuffs. As effective pressure increases we also observe an increase in ultrasonic wave velocities, dynamic elastic moduli, and $V_{P} / V_{S}$ ratio. These changes all accelerate after the onset inelastic pore collapse $\left(P^{*}\right)$, which exists between effective pressures of $10-15 \mathrm{MPa}$

3. Thermal stressing increases the permeability and decreases the ultrasonic wave velocities, dynamic elastic moduli, and $V_{P} / V_{S}$ ratio of the Neapolitan Yellow Tuff. However, the tuff from the Campanian Ignimbrite is unaffected by thermal stressing. This is the result of the loss of thermally unstable zeolites, namely phillipsite and chabazite, in Neapolitan Yellow Tuff. For example, for the sample thermally stressed to $750^{\circ} \mathrm{C}$, the permeability at an effective pressure of $5 \mathrm{MPa}$ increases by an order of magnitude relative to the ascollected material.

4. While we urge that these new laboratory data should be considered in routine ground deformation modelling, our study highlights that the physical properties of just two rocks that comprise the caldera at Campi Flegrei can be extremely heterogeneous (we also anticipate that future measurements will further expand our knowledge of such heterogeneity). These data underline the challenges for accurate ground deformation modelling at Campi Flegrei. We anticipate that no unique values of permeability or elastic moduli exist for the materials within Campi Flegrei, highlighting the need for the development of more complex ground deformation models.

Acknowledgements. We gratefully acknowledge John Bowles, Steve Boon and Neil Hughes (all UCL) for help and support during experimentation. We thank G. Orsi for the provision of the experimental materials, and Y. Lavallée for discussions. M. J. Heap acknowledges a CNRS INSU grant Étude de la stabilité des édifices volcaniques. P. Baud and P. G. Meredith acknowledge the support of a CNRS PICS grant. The reviews of Andrea Manconi, Claudia Cannatelli, Maurizio de Gennaro, one anonymous reviewer, and comments by the editor (Antonella Longo), greatly improved this manuscript.

Edited by: A. Longo

\section{References}

AGIP: Geologia e Geofisica Del Sistema Geotermico Dei Campi Flegrei, Servizi Centrali per l'Esplorazione, SERG-MMESG, San Donato, 1987.

Ascolese, E., Aurisicchio, A., Briggs-Smith, M., Mita, D. G., Perna, G., Rossi, S., and Gaeta, F. S.: Thermodynamics of waterpermeated unwelded pyroclasts, 1: equilibrium properties, J. Volcanol. Geoth. Res., 57, 219-233, 1993a.

Ascolese, E., Aurisicchio, A., Briggs-Smith, M., Mita, D. G., Perna, G., Rossi, S., and Gaeta, F. S.: Thermodynamics of waterpermeated unwelded pyroclasts, 2: non-equilibrium properties, J. Volcanol. Geoth. Res., 59, 235-251, 1993b.

Barberi, E., Cassano, E., La Torre, P. and Sbrana, A.: Structural evolution of Campi Flegrei caldera in light of volcanological and geophysical data, J. Volcanol. Geoth. Res., 48, 33-49, 1991.

Battaglia, M., Troise, C., Obrizzo, F., Pingue, F., and De Natale, G.: Evidence for fluid migration as the source of deformation at Campi Flegrei caldera (Italy), Geophys. Res. Lett., 33, L01307, doi:10.1029/2005GL024904, 2006.

Beauducel, F., De Natale, G., Obrizzo, F., and Pingue, F.: 3-D Modelling of Campi Flegrei Ground Deformations: Role of Caldera Boundary Discontinuities, Pure Appl. Geophys., 161, 13291344, 2004.

Berrino, G., Corrado, G., Luongo, G., and Toro, B.: Ground deformation and gravity changes accompanying the 1982 Pozzuoli uplift, Bull. Volcanol., 47, 187-200, 1984.

Bianchi, R., Coradini, A., Federico, C., Giberti, G., Lanciano, P., Pozzi, J. P., Sartoris, G., and Scandone, R.: Modeling of Surface Deformation in Volcanic Areas: The 1970-1972 and 19821984 Crises of Campi Flegrei, Italy, J. Geophys. Res., 92, 14139 14150, 1987.

Bianco, F., Del Pezzo, E., Saccorotti, G., and Ventura, G.: The role of hydrothermal fluids in triggering the July-August 2000 seismic swarm at Campi Flegrei, Italy: evidence from seismological and mesostructural data, J. Volcanol. Geoth. Res., 133, 229-246, 2004.

Bodnar, R. J., Cannatelli, C., De Vivo, B., Lima, A., Belkin, H. E., and Milia, A.: Quantitative model for magma degassing and ground deformation (bradyseism) at Campi Flegrei, Italy: Implications for future eruptions, Geology, 35, 791-794, 2007.

Bonafede, M.: Hot fluid migration: an efficient source of ground deformation: application to the 1982-1985 crisis at Campi FlegreiItaly, J. Volcanol. Geoth. Res., 48, 187-198, 1991.

Bonafede, M., Dragoni, M., and Quareni, F.: Displacement and stress fields produced by a centre of dilation and by a pressure source in a viscoelastic half space: application to the study of ground deformation and seismic activity at Campi Flegrei, Italy, Geophys. J. Int., 87, 455-485, 1986.

Bonafede, M. and Mazzanti, M.: Modelling gravity variations consistent with grounddeformation in the Campi Flegrei caldera (Italy), J. Volcanol. Geoth. Res., 81, 137-157. 1998.

Cappelletti, P., Cerri, G., Collettini, C., de Gennaro, M., Langella, A., Perrotta, A., and Scarpati, C.: Post-eruptive processes in the Campanian Ignimbrite, Miner. Petrol., 79, 79-97, 2003.

Cheng, C. H. and Johnston, D. H.: Dynamic and static moduli, Geophys. Res. Lett., 8, 39-42, 1981.

Chiarabba, C. and Moretti, M.: An insight into the unrest phenomena at the Campi Flegrei caldera from $\mathrm{Vp}$ and $V_{P} / V_{S}$ 
tomography, Terra Nova, 18, 373-379, doi:10.1111/j.13653121.2006.00701.x, 2006.

Chiodini, G., Caliro, S., De Martino, P., Avino, R., and Gherardi, F.: Early signals of new volcanic unrest at Campi Flegrei caldera? Insights from geochemical data and physical simulations, Geology, 40, 943-946, 2012.

Chiodini, G., Todesco, M., Caliro, S., Del Gaudio, C., Macedonio, G., and Russo, M.: Magma degassing as a trigger of bradyseismic events: the case of Phlegrean Fields (Italy), Geophys. Res. Lett., 30, 1434, doi:10.1029/2002GL016790, 2003.

Chiodini, G., Vilardo, G., Augusti, V., Granieri, D., Caliro, S., Minopoli, C., and Terranova, C.: Thermal monitoring of hydrothermal activity by permanent infrared automatic stations: results obtained at Solfatara di Pozzuoli, Campi Flegrei (Italy), J. Geophys. Res., 112, doi:10.1029/2007JB005140, 2007.

Ciccotti, M. and Mulargia, F.: Differences between static and dynamic elastic moduli of a typical seismogenic rock, Geophys. J. Int., 157, 474-477, 2004.

Ciccotti, M., Almagro, R., and Mulargia, F.: Static and dynamic moduli of the seismogenic layer in Italy, Rock Mech. Rock Eng., 37, 229-238, doi:10.1007/s00603-003-0019-7, 2004.

D’Auria, L., Giudicepietro, F., Aquino, I., Borriello, G., Del Gaudio, C., Lo Bascio, D., Martini, M., Ricciardi, G. P., Ricciolino, P., and Ricco, C.: Repeated fluid-transfer episodes as a mechanism for the recent dynamics of Campi Flegrei caldera (19892010), J. Geophys. Res., 116, doi:10.1029/2010JB007837, 2011.

David, C., Menéndez, B., and Darot, M.: Influence of stress-induced and thermal cracking on physical properties and microstructure of La Peyratte granite, Int. J. Rock Mech. Min., 36, 433-448, 1999.

de Gennaro, M., Cappelletti, P., Langella, A., Perrotta, A., and Scarpati, C.: Genesis of zeolites in the Neapolitan Yellow Tuff: geological, volcanological and mineralogical evidences, Contrib. Mineral. Petr., 139, 17-35, 2000.

de Gennaro, M. and Colella, C.: Use of thermal analysis for the evaluation of zeolite content in mixtures of hydrated phases, Thermochim. Ac., 154, 345-353, 1989.

de Gennaro, M., Petrosino, S., Conte, M. T., Munno, R., and Colella, A.: Zeolite chemistry and distribution in a Neapolitan Yellow Tuff deposit, Eur. J. Mineral., 2, 779-786, 1990.

de Lorenzo, S., Gasparini, P., Mongelli, F., and Zollo, A.: Thermal state of the Campi Flegrei caldera inferred from seismic attenuation tomography, J. Geodynam., 32, 467-486, 2001.

De Natale, G. and Pingue, F.: Ground deformations in collapsed caldera structures, J. Volcanol. Geoth. Res., 57, 19-38, 1993.

De Natale, G., Troise, C., and Pingue, F.: A mechanical fluiddynamical model for ground movements at Campi Flegrei caldera, J. Geodynam., 32, 487-517, 2001.

De Natale, G., Troise, C., Pingue, F., Mastrolorenzo, G., Pappalardo, L., Battaglia, M., and Boschi, E.: The Campi Flegrei caldera: Unrest mechanisms and hazards, Geol. Soc. Lond. Special Publications, 269, 25-45, 2006.

De Vivo, B., Rolandi, G., Gans, P. B., Calvert, A., Bohrson, W. A., Spera, F. J., and Belkin, H. E.: New constraints on the pyroclastic eruptive history of the Campanian volcanic Plain (Italy), Mineral. Petrol., 73, 47-65, 2001.

Deino, A. L., Orsi, G., De Vita, S., and Piochi, M.: The age of the Neapolitan Yellow Tuff caldera-forming eruption (Campi Flegrei caldera - Italy) assessed by 40Ar/39Ar dating method, J. Volcanol. Geoth. Res., 133, 157-170, 2004.

Dzurisin, D.: Volcano Deformation, Chichester, UK, Springer, ISBN:978-3540426424, 2006.

Eissa, E. A. and Kazi, A.: Relation between static and dynamic Young's moduli of rocks, Int. J. Rock Mech. Min., 25, 479-482, 1989.

Gaeta, F. S., De Natale, G., Peluso, F., Mastrolorenzo, G., Castagnolo, D., Troise, C., Pingue, F., Mita, D. G., and Rossano, S.: Genesis and evolution of unrest episodes at Campi Flegrei caldera: the role of thermal fluid-dynamical processes in the geothermal system, J. Geophys. Res., 103, 20921-20933, 1998.

Gaeta, F. S., Peluso, F., Arienzo, I., Castagnolo, D., De Natale, G., Milano, G., Albanese, C., and Mita, D. G.: A physical appraisal of a new aspect of bradyseism: the miniuplifts, J. Geophys. Res., 108, B8, 2363, doi:10.1029/2002JB001913, 2003.

Giberti, G., Yven, B., Zamora, M. and Vanorio, T., Database on laboratory measured data on physical properties of rocks of Campi Flegrei volcanic area (Italy), in: Geophysical Exploration of the Campi Flegrei (Southern Italy) Caldera' Interiors: Data, Methods and Results, edited by: Zollo, A., Capuano, P., and Corciulo, M. Doppiavoce, Naples, ISBN-10: 88-89972-04-1, ISBN-13: 97888-89972-04-5, 2006.

Gottsmann, J., Camacho, A. G., Tiampo, K. F., and Fernandez, J.: Spatiotemporal variations in vertical gravity gradients at the Campi Flegrei caldera (Italy): a case for source multiplicity during unrest?, Geophys. J. Int., 167, 1089-1096, 2006.

Guéguen, Y. and Palciauskas, V.: Introduction to the Physics of Rocks, Princeton University Press, Princeton, New Jersey, 1994.

Heap, M. J. and Faulkner, D. R.: Quantifying the static elastic evolution of crystalline rock approaching failure, Int. J. Rock Mech. Min., 45/4, 564-573, 2008.

Heap, M. J., Vinciguerra, S., and Meredith, P. G.: The evolution of elastic moduli with increasing damage during cyclic stressing of a basalt from Mt. Etna volcano, Tectonophysics, 471, 153-160, 2009.

Heap, M. J., Lavallée, Y., Laumann, A., Hess, K.-U., Meredith, P. G., and Dingwell, D. B.: How tough is tuff in the event of fire?, Geology, 40, 311-314, 2012.

Homand-Etienne, F. and Troalen, J.-P.: Behaviour of granites and limestones subjected to slow and homogenous temperature changes, Eng. Geol., 20, 219-233, 1984.

Hurwitz, S., Christiansen, L. B., and Hsieh, P. A.: Hydrothermal fluid flow and deformation in large calderas: inferences from numerical simulations, J. Geophys. Res., 112, B02206, doi:10.1029/2006JB004689, 2007.

Jones, C., Keaney, G., Meredith, P. G., and Murrell, S. A. F.: Acoustic emission and fluid permeability measurements on thermally cracked rocks, Phys. Chem. Earth, 22, 13-17, 1997.

Keshavarz, M., Pellet, F. L., and Loret, B.: Damage and changes in mechanical properties of a Gabbro thermally loaded up to $1000^{\circ} \mathrm{C}$, Pure Appl. Geophys., 167, 1511-1523, doi:10.1007/s00024-010-0130-0, 2010.

Kolzenburg, S., Heap, M. J., Lavallée, Y., Russell, J. K., Meredith, P. G., and Dingwell, D. B.: Strength and permeability recovery of tuffisite-bearing andesite, Solid Earth, 3, 191-198, doi:10.5194/se-3-191-2012, 2012.

Lanari, R., Berardino, P., Borgstrom, S., Del Gaudio, C., De Martino, P., Fornaro, G., Guarino, S., Ricciardi, G. P., Sansosti, E., 
and Lundgren, P.: The use of IFSAR and classical geodetic techniques for caldera unrest episodes: application to the Campi Flegrei uplift event of 2000, J. Volcanol. Geoth. Res., 133, 247-260, 2004.

Langella, A., Bish, D. L., Cappelletti, P., Cerri, G., Colella, A., de Gennaro, R., Graziano, S. F., Perrotta, A., Scarpati, C., and de Gennaro, M.: New insights into the mineralogical facies distribution of Campanian Ignimbrite, a relevant Italian industrial material, Appl. Clay Sci., 72, 55-73, 2013.

Lima, A., De Vivo, B., Spera, F. J., Bodnar, R. J., Milia, A., Nunziata, C., Belkin, H. E., and Cannatelli, C.: Thermodynamic model for uplift and deflation episodes (bradyseism) associated with magmatic-hydrothermal activity at the Campi Flegrei (Italy), Earth-Sci. Rev., 97, 44-58, 2009.

Lockner, D.: The role of acoustic emission in the study of rock fracture, Int. J. Rock Mech. Min., 30, 883-889, 1993.

Lundgren, P., Usai, S., Sansosti, E., Lanari, R., Tesauro, M., Fornaro, G., and Berardino, P.: Modeling surface deformation observed with synthetic aperture radar interferometry at Campi Flegrei caldera, J. Geophys. Res., 106, 19355-19366, 2001.

Manconi, A., Walter, T. R., and Amelung, F.: Effects of mechanical layering on volcano deformation, Geophys. J. Int., 170, 952-958, 2007.

Manconi, A., Walter, T. R., Manzo, M., Zeni, G., Tizzani, P., Sansosti, E., and Lanari, R.: On the effects of 3-D mechanical heterogeneities at Campi Flegrei caldera, southern Italy, J. Geophys. Res., B08405, doi:10.1029/2009JB007099, 2010.

Mogi, K.: Relations between the eruptions of various volcanoes and the deformations of the ground surfaces around them, Bull. Earthq. Res. Inst., Univ. Tokyo, 36, 99-134, 1958.

Nara, Y., Meredith, P. G., Yoneda, T., and Kaneko, K.: Influence of macro-fractures and micro-fractures on permeability and elastic wave velocities in basalt at elevated pressure, Tectonophysics, 503, 52-59, 2011.

Orsi, G., De Vita, S., and di Vito, M.: The restless, resurgent Campi Flegrei nested caldera (Italy): constraints on its evolution and configuration, J. Volcanol. Geoth. Res., 74, 179-214, 1996.

Peluso, F. and Arienzo, I.: Experimental determination of permeability of Neapolitan Yellow Tuff, J. Volcanol. Geoth. Res., 160, 125-136, 2007.

Plattner, C., Amelung, F., Baker, S., Govers, R. and Poland, M., 2013. The role of viscous magma mush spreading in volcanic flank motion at Kīlauea Volcano, Hawai'i, J. Geophys. Res., 118, 2474-2487, 2013.

Ricci, T., Barberi, E., Davis., M. S., Isaia, R., and Nave, R.: Volcanic risk perception in the Campi Flegrei area, J. Volcanol. Geoth. Res., 254, 118-130, 2013.

Rolandi, G., Bellucci, F., Heizler, M. T., Belkin, H. E. and De Vivo, B.: Tectonic controls on the genesis of ignimbrites from the Campanian Volcanic Zone, southern Italy, Mineral. Petrol, 79, 3-31, 2003.

Rosi, M. and Sbrana, A.: Phlegraean Fields, Quaderni de "La Ricerca Scientifica": Consiglio Nazionale delle Ricerche Monograph 114, 9, 175, 1987.

Rutter, E.: On the nomenclature of mode of failure transitions in rocks, Tectonophysics, 122, 381-387, 1986.

Saccorotti, G., Petrosino, S., Bianco, F., Castelluccio, M., Galluzzo, D., La Rocca, M., Del Pezzo, E., Zaccarelli, L., and Cusano, P.: Seismicity associated with the 2004-2006 renewed ground uplift at Campi Flegrei Caldera, Italy, Phys. Earth Planet. Inter., 165, 14-24, 2007.

Simmons, G. and Brace, W. F.: Comparison of static and dynamic measurements of compressibility of rocks, J. Geophys. Res., 70, 5649-5656, 1965.

Todesco, M., Rinaldi, A. P., and Bonforte, A.: Modeling of unrest signals in heterogeneous hydrothermal systems, J. Geophys. Res., 115, B09213, doi:10.1029/2010JB007474, 2010.

Trasatti, E., Casu, F., Giunchi, C., Pepe, S., Solaro, G., Tagliaventi, S., Berardino, P., Manzo, M., Pepe, A., Ricciardi, G. P., Sansosti, E., Tizzani, P., Zeni, G., and Lanari, R.: The 2004-2006 uplift episode at Campi Flegrei caldera (Italy): Constraints from SBAS-DInSAR ENVISAT data and Bayesian source inference, Geophys. Res. Lett., 35, L07308, doi:10.1029/2007GL033091, 2008.

Troiano, A., Di Giuseppe, Petrillo, Z., Troise, C., and De Natale, G.: Ground deformation at calderas driven by fluid injection: modelling unrest episodes at Campi Flegrei (Italy), Geophys. J. Int., 187, 833-847, 2011.

Troise, C., Castagnolo, D., Peluso, F., Gaeta, F. S., Mastrolorenzo, G., and De Natale, G.: A 2-D mechanical-thermal fluiddynamical model for geothermal systems at calderas: an application to Campi Flegrei, J. Volcanol. Geoth. Res., 109, 1-12, 2001.

Troise, C., De Natale, G., Pingue, F., Obrizzo, F., De Martino, P., Tammaro, U., and Boschi, E.: Renewed ground uplift at Campi Flegrei caldera (Italy): New insight on magmatic processes and forecast, Geophys. Res. Lett., 34, doi:10.1029/2006GL028545, 2007.

Valentino, G. M., Cortecci, G., Franco, E., and Stanzione, D.: Chemical and isotopic compositions of minerals and waters from the Campi Flegrei volcanic system, Naples, Italy, J. Volcanol. Geoth. Res., 91, 329-344, 1999.

Vanorio, T., Virieux, J., Capuano, P., and Russo, G.: Threedimensional seismic tomography from $\mathrm{P}$ wave and $\mathrm{S}$ wave microearthquake travel times and rock physics characterization of the Campi Flegrei Caldera, J. Geophys. Res., 110, B03201, doi:10.1029/2004JB003102, 2005.

Vinciguerra, S., Meredith, P. G., and Hazzard, J.: Experimental and modeling study of fluid pressure-driven fractures in Darley Dale sandstone, Geophys. Res. Lett., L09609, doi:10.1029/2004GL019638, 2004.

Vinciguerra, S., Del Gaudio, P., Mariucci, M. T., Marra, F., Meredith, P. G., Montone, P., Pierdominici, S., and Scarlato, P.: Physical properties of tuffs from a scientific borehole at Alban hills volcanic district (central Italy), Tectonophysics, 471, 161-169, 2009.

Vinciguerra, S., Trovato, C., Meredith, P. G., Benson, P. M., Troise, C., and De Natale, G.: Understanding the seismic velocity structure of Campi Flegrei caldera (Italy): from the laboratory to the field scale, Pure Appl. Geophys., 163, 2205-2221, 2006.

Wohletz, K., Civetta, L., and Orsi, G.: Thermal evolution of the Phlegraean magmatic system, J. Volcanol. Geoth. Res., 91, 381414, 1999.

Wong, T.-F. and Baud, P.: The brittle transition in rocks: a review, J. Struct. Geol., 44, 25-53, 2012.

Zamora, M., Sartoris, G., and Chelini, W.: Laboratory measurements of ultrasonic wave velocities in rocks from the Campi Flegrei volcanic system and their relation to other field data, J. Geophys. Res., 99, 13553-13561, 1994. 
Zhu, W. and Wong, T.-F.: The transition from brittle faulting to cataclastic flow: permeability evolution, J. Geophys. Res., 102, 3027-3041, 1997.
Zhu, W., Baud, P., Vinciguerra, S., and Wong, T.-F.: Micromechanics of brittle faulting and cataclastic flow in Alban Hills tuff, J. Geophys. Res., 116, B06209, doi:10.1029/2010JB008046, 2011. 